\title{
Numerical Evaluation of the Weldability of the Low Alloy Ferritic Steels T/P23 and T/P24
}

\author{
Carlos Roberto Xavier ${ }^{\mathrm{a} *}$, Horácio Guimarães Delgado Junior ${ }^{\mathrm{b}}$, José Adilson de Castro ${ }^{\mathrm{b}}$ \\ aUniFOA/Petrobras \\ Av. Paulo E. A. Abrantes, 1325, Três Poços, CEP 27240-560, Volta Redonda, RJ, Brazil

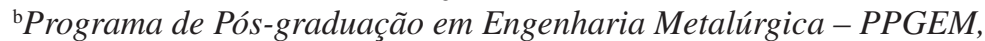 \\ Universidade Federal Fluminense, Polo Universitário de Volta Redonda, \\ Av. dos Trabalhadores, 420, Vila Santa Cecília, CEP 27255-125, Volta Redonda, RJ, Brazil
}

Received: November 9, 2010; Revised: February 26, 2011

\begin{abstract}
A model based on transport equations was numerically implemented by the finite volume method (FVM) in a computational code in order to simulate the influence of the heat input, base metal thickness and preheating temperature on the thermal evolution and the cooling rate during the welding of the low alloy ferritic steels T/P23 and T/P24. As a consequence, it was possible to evaluate qualitatively the microstructure at the heat affected zone (HAZ) of these steels when a single weld bead was deposited on their surface and calculate the maximum hardness reached at this region. Goldak`s double-ellipsoid heat source model for power density distribution was utilized in order to obtain a good estimate of the cooling rate and dimensions of the fusion zone (FZ). The results are discussed in light of previous work and good agreement between experimental and simulated results was verified.
\end{abstract}

Keywords: numerical evaluation, T/P23 and T/P24 steels, weldability, hardness

\section{Introduction}

The 2,25Cr-1Mo steels (T/P22) have been used for a long time and are largely employed in applications submitted to high temperatures such as steam generators and pressure vessels for power plants and petroleum refineries. However, the necessity for higher efficiencies and increasing requirements for lower emissions has driven to the operation of fossil fuel power plants with continuous increase of the process steam temperature. Thus, in order to assure higher steam temperature it is necessary the development of higher strength and creep resistant materials. In general, the ferritic Cr-Mo alloy steels for elevated temperature applications were improved by specific alloy addition such as $\mathrm{V}, \mathrm{Nb}, \mathrm{W}$ and $\mathrm{N}$. Thus, the alloying addition to the T/P22 lead to the development of the modified low alloy ferritic steels T/P23 and T/P24 that have enhanced their properties at elevated temperature such as strength and creep resistance. Besides of enhanced performance at elevated temperatures, it is also claimed an improved weldability of the modified steels T/P23 and T/P24 ${ }^{1-10}$. Due to these characteristics, T/P23 and T/P24 steels are becoming very attractive for applications in power plants, petroleum refineries and petrochemical industry.

Due to the importance and increasing utilization, it is very useful a better understanding of the weldability of these steels since welding procedure is generally present during manufacture, assemble or repair of components and equipments. Numerical simulations are currently used to investigate optimized welding parameters which lead to better and safety structural projects. However, the predictions of metallurgical transformations and simultaneous properties development on the heat-affected zone are usually neglected. In this work, the numerical simulation is applied based on a computer code, specially developed by the authors for the simulation of welding process and adapted for the T/P23 and T/P24 steels. The model is used to get a better understanding of the metallurgical transformation that take places during welding of the T/P23 and T/P24 steels. The software developed for this application is a home made program which solves the energy equation in a complex geometry with dynamically mesh adaptation and allows the implementation of complex boundary conditions regarding to the welding arc and metal deposition shapes. This work differs from previous ones mainly due to the boundary conditions considered for the heat source of the welding arc and complete coupling of the temperature dependence on the thermophysical properties.

\section{Metallurgy and Welding of T/P23 and T/P24}

The development of the new grades T/P23 (ASTM A 213/A335) and T/P24 (ASTM A 213) had as basis the T/P22 (ASTM A 213/A335) (Table 1) by the addition and/or substitution of alloying aiming its strengthening mainly due to the precipitation hardening. The physical properties and the oxidation resistance of the T/P23 and T/P24 are similar to the T/P22 due to the same basic compositions and structure, however, significant difference is obtained in mechanical properties and creep resistance. For instance, the values of yielding strength for T/P23 and T/P24 are almost two times higher than T/P22 in a wide range of temperature ${ }^{3}$.

The addition of the elements $\mathrm{V}$ and $\mathrm{Nb}(\mathrm{V}$ and $\mathrm{Ti}$ to the T/P24) which, combined with the elements $\mathrm{C}$ and/or $\mathrm{N}$, can form carbides, nitrides or carbo-nitrides of MX type ( $\mathrm{M}$ mean the metallic elements while $\mathrm{X}$ the expression $\mathrm{C}+\mathrm{N}$ ), that promotes a fine precipitation in the matrix, increasing the strength of the steels. In the case of T/P23 steel, the substitution of Mo by W is carried out to increase the creep resistance, achieving higher strength mainly by the combination of $\mathrm{W}$ in solid solution and the dispersion of $\mathrm{Nb}$ and $\mathrm{V}$ carbides in a tempered bainitic matrix. The $\mathrm{B}$ addition increases the toughness and creep resistance as well as retards the transformation into ferrite. Besides the use of the new steels grades for tubes and pipes, is also expected a possible application in heavy wall pressure vessels ${ }^{1}$. 
Table 1. Chemical composition of new grades T/P23 and T/P24 and the older T/P22.

\begin{tabular}{cccc}
\hline $\begin{array}{c}\text { (\%) } \\
\text { weight }\end{array}$ & $\begin{array}{c}\text { T/P22 } \\
\text { (ASTM A 213/A335) }\end{array}$ & $\begin{array}{c}\text { T/P23 } \\
\text { (ASTM A 213/A335) }\end{array}$ & $\begin{array}{c}\text { T/P24 } \\
\text { (ASTM A 213) }\end{array}$ \\
\hline $\mathrm{C}$ & máx. 0.15 & $0.04-0.10$ & $0.05-0.10$ \\
$\mathrm{Si}$ & $0.25-1.00$ & máx. 0.50 & $0.15-0.45$ \\
$\mathrm{Mn}$ & $0.30-0.60$ & $0.10-0.60$ & $0.30-0.70$ \\
$\mathrm{Cr}$ & $1.90-2.60$ & $1.90-2.60$ & $2.20-2.60$ \\
$\mathrm{Mo}$ & $0.87-1.13$ & $0.05-0.30$ & $0.90-1.10$ \\
$\mathrm{~V}$ & - & $0.20-0.30$ & $0.20-0.30$ \\
$\mathrm{~W}$ & - & $1.45-1.75$ & - \\
$\mathrm{Al}$ & - & máx. 0.030 & máx. 0.020 \\
$\mathrm{~B}$ & - & $0.0005-0.0060$ & $0.0015-0.0070$ \\
$\mathrm{~N}$ & - & máx. 0.030 & máx. 0.012 \\
$\mathrm{Nb}$ & - & $0.02-0.08$ & - \\
$\mathrm{Ti}$ & - & - & $0.05-0.10$ \\
\hline
\end{tabular}

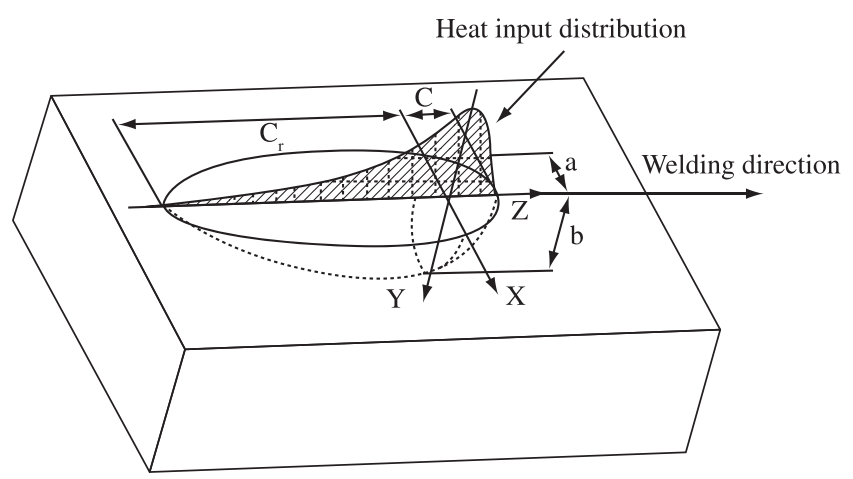

Figure 1. Schematic model for double-ellipsoid heat sourcel ${ }^{11}$.

Because of lower carbon content, T/P23 and T/P24 presents a martensitic structure with hardness limited to $350-360 \mathrm{HV} 10$ that is compatible with hardness allowed for power generation application ${ }^{4}$. This behavior is very interesting in the case of thin-walled tubes (wall thickness $<10 \mathrm{~mm}$ ) because it allows welding without post weld heat treatment (PWHT) and attain improved weldability ${ }^{1-10}$. The possibility of welding without PWHT and even preheating becomes the use of T23 and T24 very attractive since such procedures, although useful to improved the welded joint properties such as hardness and toughness, in practice can be difficult to carry out on services, increasing cost and can produce unconformities as structural distortion and reheat cracking. Although the hardness remains at similar level in the thick-walled pipes welding, PWHT and preheating are frequently used in the case of P23 and P24 in order to improve the toughness and avoid the susceptibility to hydrogen cold cracking ${ }^{4,8,9}$.

\section{Numerical Modeling}

\subsection{Model features}

This work aimed to evaluate by means of numerical simulation the effects of the heat input, thickness and preheating temperature of the base metal on the transformations that occur in the HAZ of the T/P23 and T/P24 steels in order to predict their properties when welded. To address these features it is necessary to predict the temperature field coupled with dynamically welding process evolution
Table 2. Welding parameters.

\begin{tabular}{cccc}
\hline $\begin{array}{c}\text { Arc voltage } \\
(\mathrm{V})\end{array}$ & $\begin{array}{c}\text { Welding current } \\
(\text { Amp })\end{array}$ & $\begin{array}{c}\text { Welding speed } \\
(\mathrm{mm} / \mathrm{s})\end{array}$ & $\begin{array}{c}\text { Heat input } \\
\left(\mathrm{kJ} . \mathrm{mm}^{-1}\right)\end{array}$ \\
\hline 20 & 150 & 6 & 0.5 \\
20 & 150 & 3 & 1.0 \\
20 & 150 & 2 & 1.5 \\
20 & 150 & 1.5 & 2.0 \\
20 & 150 & 1.2 & 2.5 \\
25 & 200 & 1.25 & 4.0 \\
\hline
\end{tabular}

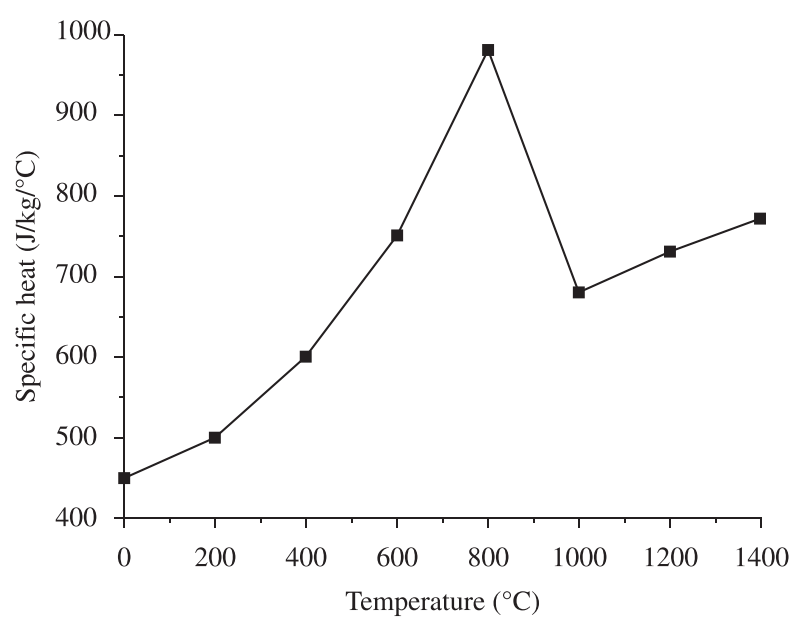

Figure 2. Temperature-dependent specific heat assumed for both T/P23 and $\mathrm{T} / \mathrm{P} 24$.

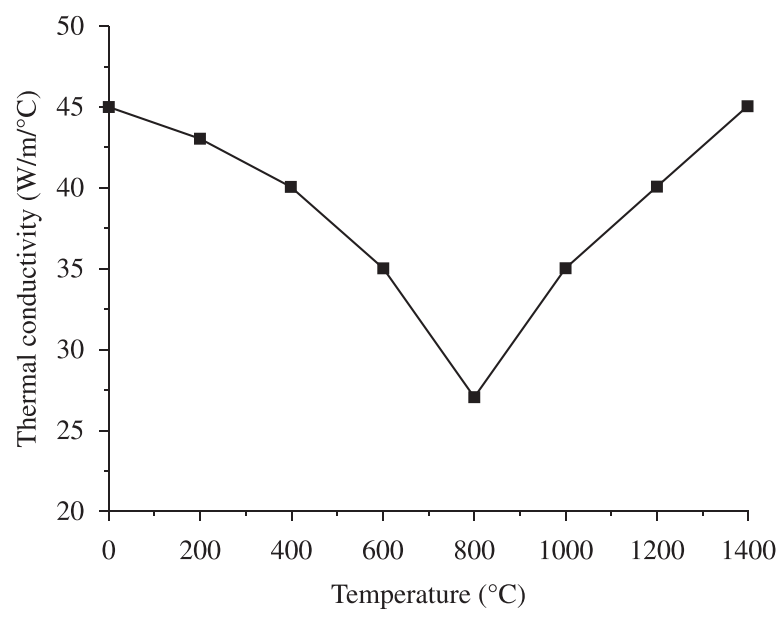

Figure 3. Temperature-dependent thermal conductivity assumed for both $\mathrm{T} / \mathrm{P} 23$ and T/P24.

and thermophysical properties. In order to model the process the phenomena of heat transfer by radiation convection and conduction are taking into account coupled with mass transfer, melting and solidification. The thermophysical properties were assumed as composition and temperature dependent. The energy equation for a general coordinate system is represented in compact form as shown in Equation 1. In Equation 1, $\rho$ is the density of the steel, $\mathrm{C}_{\mathrm{p}}$ is the specific heat, $\mathrm{k}$ is thermal conductivity, $u$ is velocity field, which accounts for 
Table 3. Welding and double-ellipsoid model parameters.

\begin{tabular}{|c|c|c|c|c|}
\hline $\begin{array}{l}\text { Arc voltage } \\
\quad(\text { Volt })\end{array}$ & $\begin{array}{l}\text { Welding current } \\
\text { (Amp) }\end{array}$ & $\begin{array}{l}\text { Welding speed } \\
\qquad(\mathrm{mm} / \mathrm{s})\end{array}$ & $\begin{array}{l}\text { Heat input } \\
\left(\mathrm{kJ} . \mathrm{mm}^{-1}\right)\end{array}$ & $\begin{array}{l}\text { Double-ellipsoid model parameters } \\
\qquad(\mathrm{mm})\end{array}$ \\
\hline 20 & 150 & 6 & 0.5 & $a_{r}=16 ; a_{f}=10 ; b=2.0 ; c=4.0$ \\
\hline 20 & 150 & 3 & 1.0 & $a_{r}=18 ; a_{f}=10 ; b=3.0 ; c=4.5$ \\
\hline 20 & 150 & 2 & 1.5 & $a_{r}=18 ; a_{f}=12 ; b=3.5 ; c=4.5$ \\
\hline 20 & 150 & 1.5 & 2.0 & $a_{r}=20 ; a_{f}=12 ; b=4.0 ; c=5.0$ \\
\hline 20 & 150 & 1.2 & 2.5 & $a_{r}=22 ; a_{f}=12 ; b=4.5 ; c=5.5$ \\
\hline 25 & 200 & 1.25 & 4.0 & $a_{r}=24 ; a_{f}=14 ; b=5.5 ; c=7.0$ \\
\hline
\end{tabular}

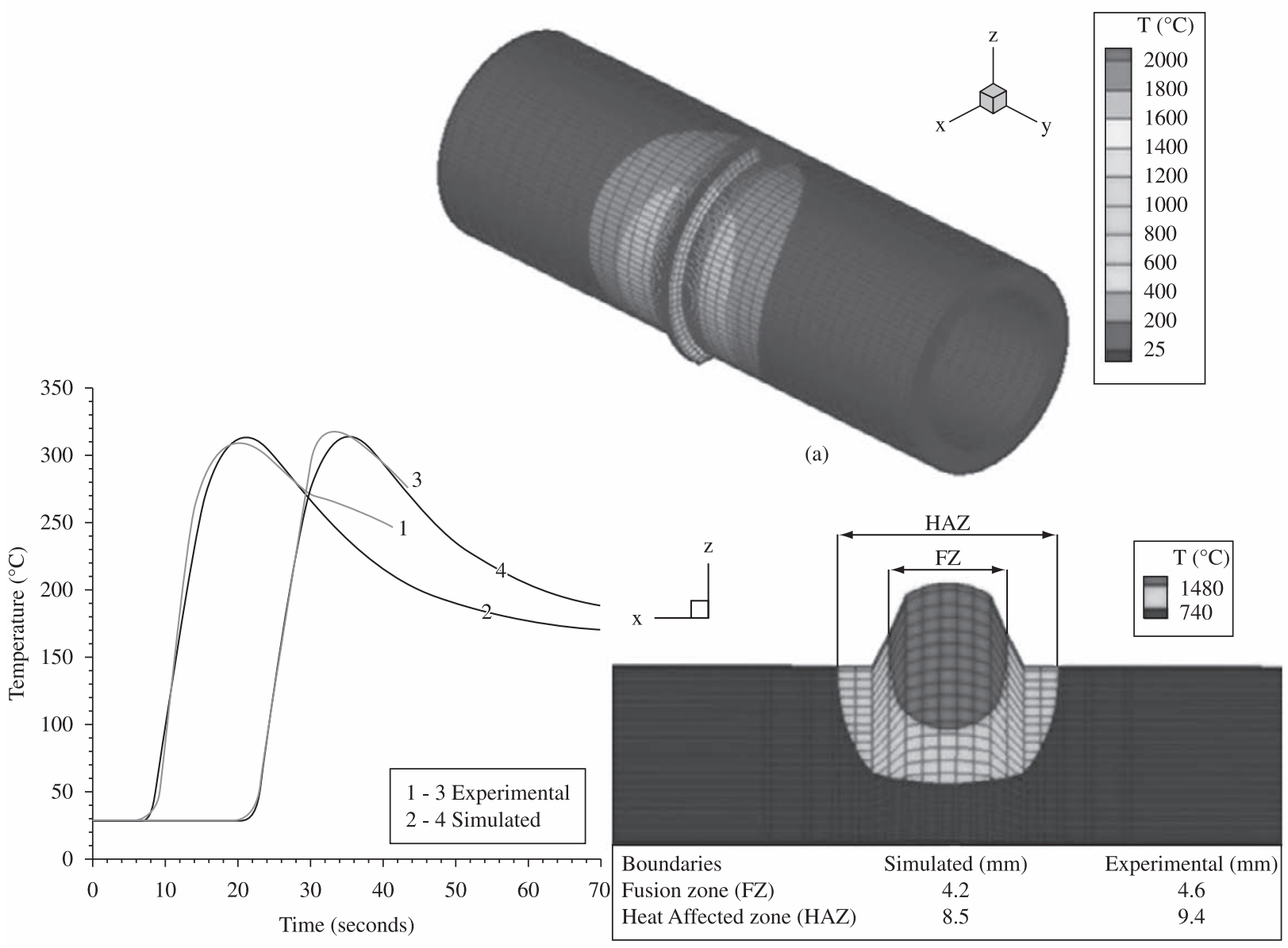

(b)

(c)

Figure 4. a) Numerical simulation of T/P23 and T/P24; b) numerical and measured temperatures; and c) welding numerical simulation of the HAZ and bead shape.

buoyancy driven flow in the liquid pool or moving mesh to match the geometry changes due to metal deposition. T is the temperature field and $\mathrm{S}$ is the source term, which accounts for all source or sink due to phase transformations, melting and solidification. Details of the numerical solution and of the Equation 1 is presented in Appendix A.

$$
\frac{\partial}{\partial t}\left(\rho c_{p} T\right)+\operatorname{div}\left[\rho c_{p}(\vec{u}) T\right]=\operatorname{div}[k(\operatorname{grad}(T))]+S
$$

\subsection{Model assumptions, initial and boundary conditions and source terms}

For the initial condition is assumed that the workpiece is uniformly at a given temperature and composition of the metal base. For each time step the geometry is actualized after metal deposition according to the assumed welding speed and amount of metal deposition. The source terms of Equation $1(\mathrm{~S})$ are due to the heat of melting and re solidification in addition to the imposed source given 


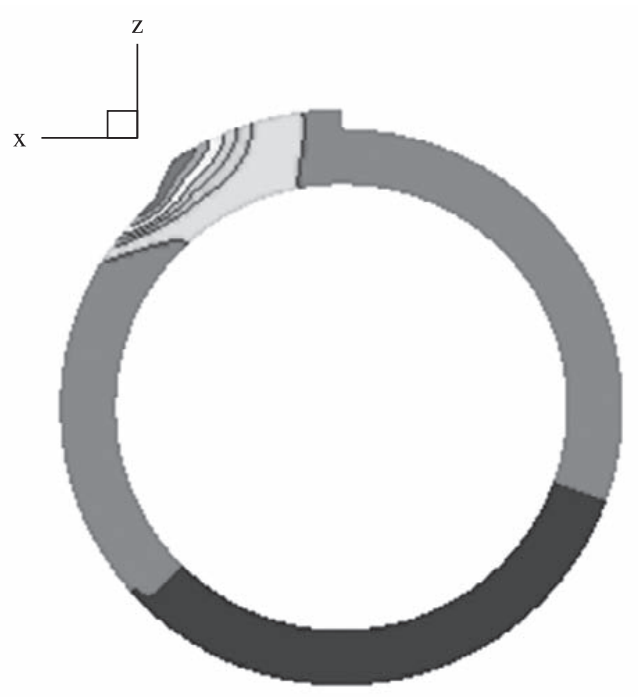

(a)

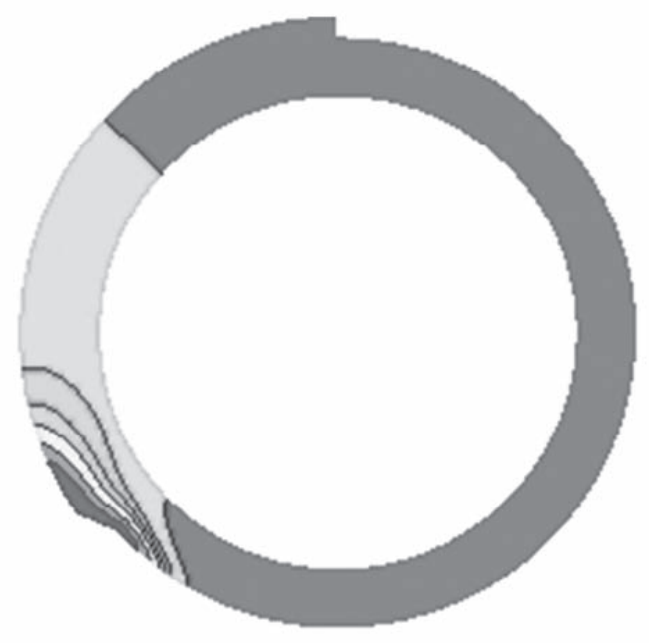

(b)
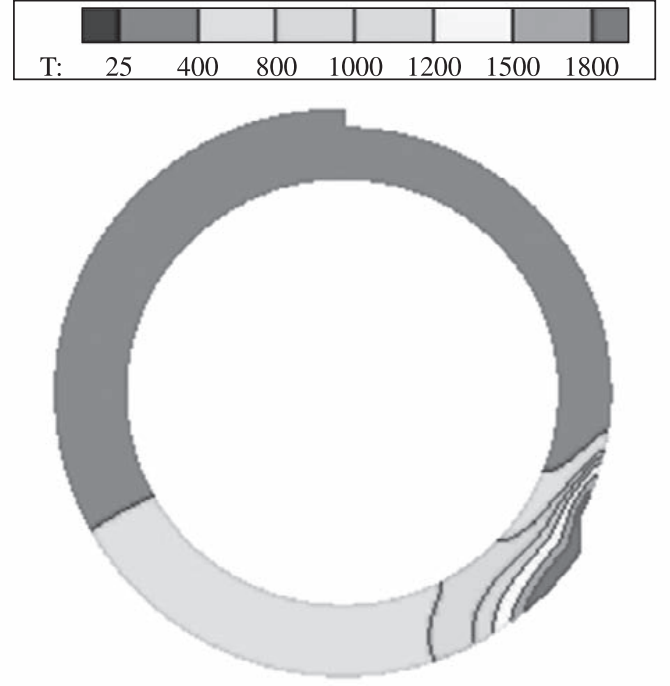

(c)

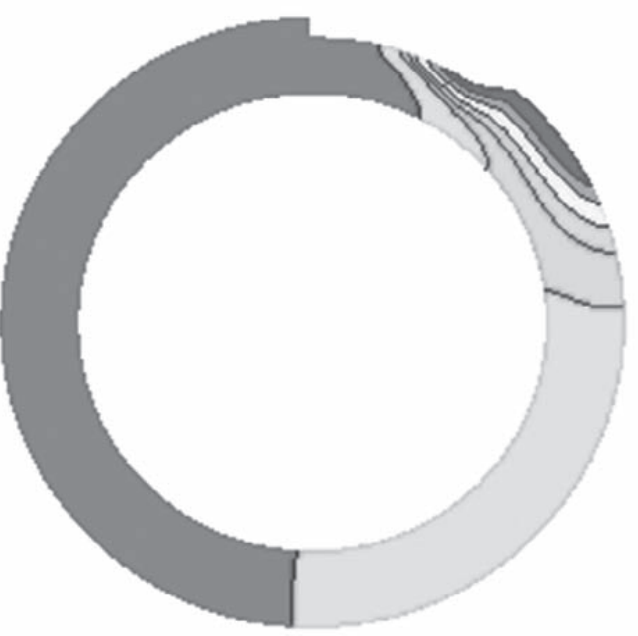

(d)

Figure 5. Effects of heat input of $1.0 \mathrm{~kJ} \cdot \mathrm{mm}^{-1}$ for $10 \mathrm{~mm}$ workpiece on temporal and spatial temperature distribution $\left({ }^{\circ} \mathrm{C}\right)$.

by the Goldak's double ellipsoid model used for heat input of each control volume. The shape and geometry of the welding deposition are assumed to match the mass addition and model parameters for Goldak's double ellipsoid heat source. Regarding to the boundary conditions it is consided the effects of convective and radiative fluxes while the heat input furnished by the torch is modeled by the power distribution given by the moving Goldak's double-ellipsoid heat source model ${ }^{11}$ (Figure 1). The Goldak's double ellipsoid heat source model is used to calculate volumetric heat flux distributions density in the surroundings of the welding pool. The double-ellipsoid model presents good agreement with experimental data for welding process simulation with shallow and deep penetration and for estimate the 800 to $500{ }^{\circ} \mathrm{C}$ cooling time $\left(t_{8 / 5}\right)^{11}$.

The model is a combination of two ellipses: one in the front quadrant of the heat source and the other in the rear quadrant. In this work became necessary to carry out a small adjustment in the heat source, which was initially described for plate welding in order to make it suitable for circumferential welding. Thus, the arbitrary spatial location within the heat source is calculated by using cylindrical coordinate system (Equations 2 and 3). Equations 2 and 3 set up the heat flux distributions inside the front and rear quadrant of the heat source respectively. The model is defined as a function of position and time together with a number of parameters that affect the heat flux magnitude and distribution.

$$
\begin{aligned}
& q_{r}(x, y, z)=\frac{6 \sqrt{3} f_{r} Q}{a b_{r} c \pi \sqrt{\pi}} e^{-3 \frac{(R \theta)^{2}}{a_{r}{ }^{2}}} e^{-3 \frac{y^{2}}{b^{2}}} e^{-3 \frac{(R-r)^{2}}{c^{2}}} \\
& q_{f}(x, y, z)=\frac{6 \sqrt{3} f_{f} Q}{a b_{f} c \pi \sqrt{\pi}} e^{-3 \frac{(R \theta)^{2}}{a_{f}^{2}}} e^{-3 \frac{y^{2}}{b^{2}}} e^{-3 \frac{(R-r)^{2}}{c^{2}}}
\end{aligned}
$$

where $R$ is the outer radius, $\theta$ the radial angle in radian and $r=\sqrt{x^{2}+z^{2}}$ is the spatial radial position. The heat input rate $Q=\eta V I$ is determined by welding operational parameters current (I), voltage (V) and thermal efficiency $\eta$, respectively. The factors $f_{f}$ and $f_{r}$ denote the fraction of the heat deposited in the front and rear quadrant respectively, which are set up to attain $f_{f}+f_{r}=2$. The $a_{f}, b$, 


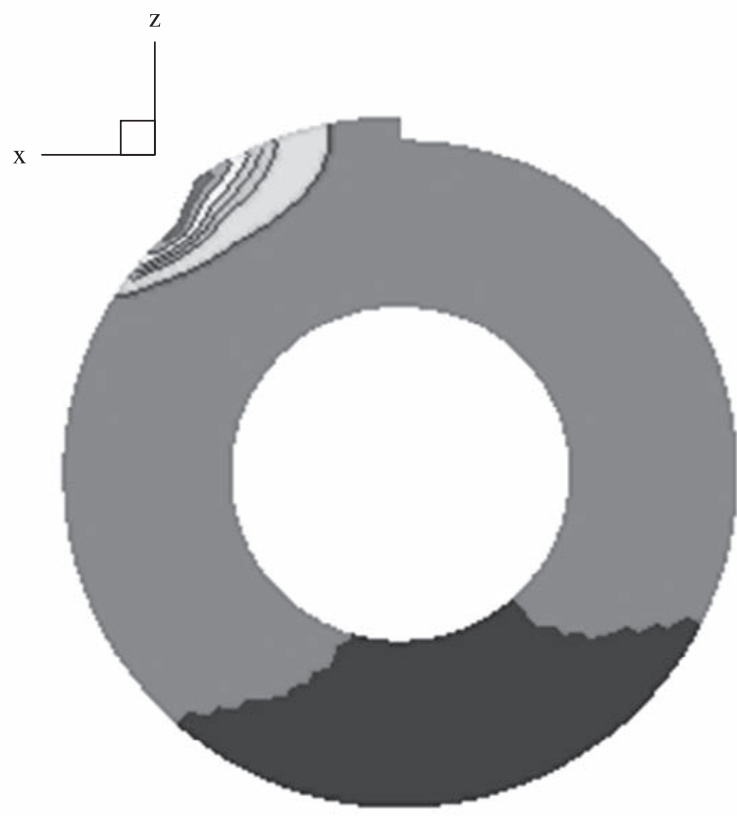

(a)

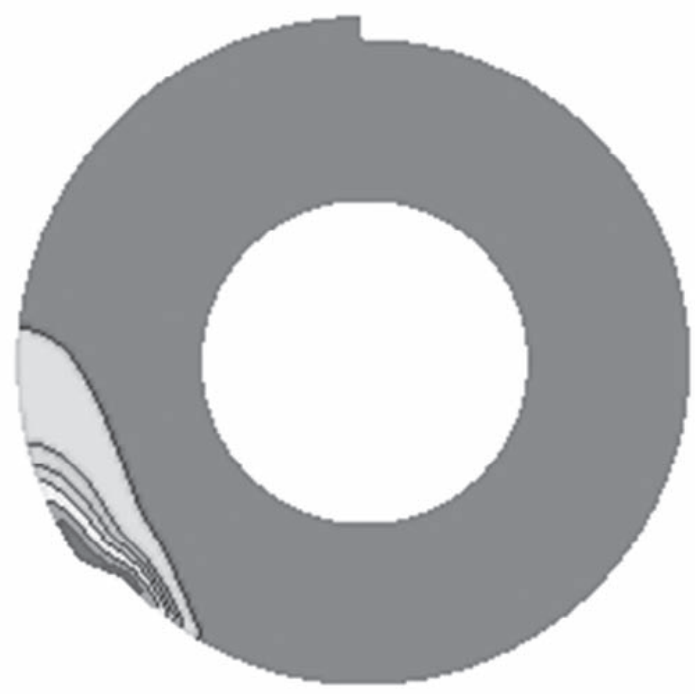

(b)
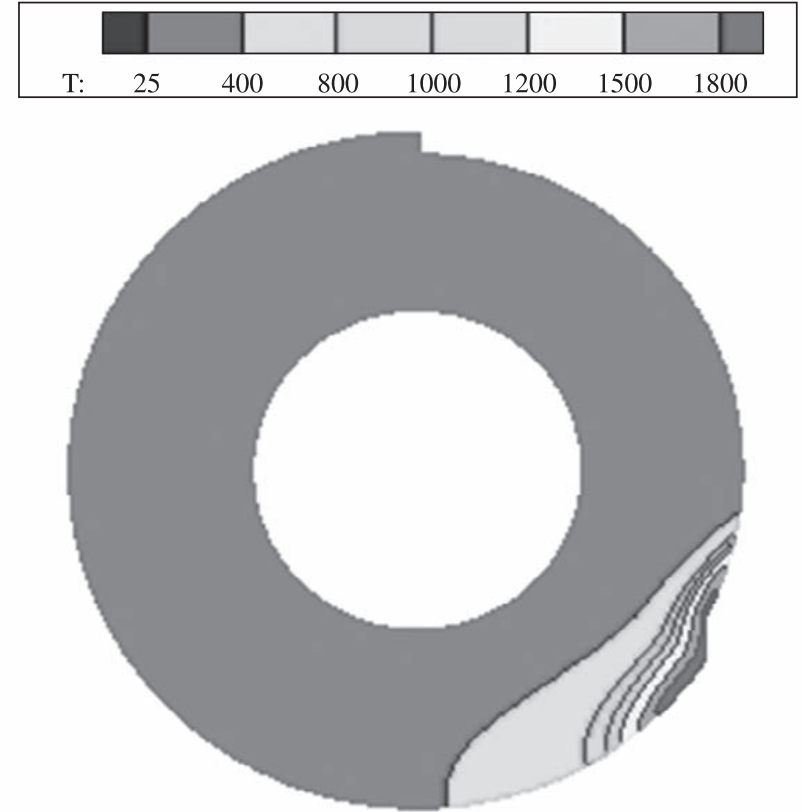

(c)

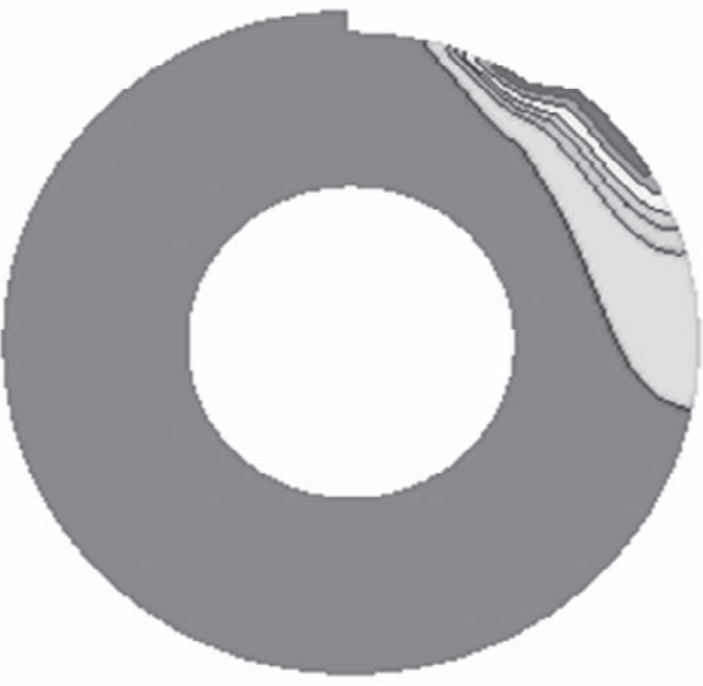

(d)

Figure 6. Effects of heat input of $1.0 \mathrm{~kJ} \cdot \mathrm{mm}^{-1}$ for $25 \mathrm{~mm}$ workpiece on temporal and spatial temperature distribution $\left({ }^{\circ} \mathrm{C}\right)$.

$c$ and $a_{r}$ are source constant parameters that define the size and shape of the ellipses, therefore the heat source distribution. In this work were used six different values for heat input (Table 2) compatible with the values used normally in welding processes. The welding thermal efficiency $\eta$ parameter was considered unitary.

The cooling boundary conditions between the workpiece and environment by means of convection and radiation are calculated by Equations 4 and 5, respectively.

$$
\begin{aligned}
& q_{c}=h\left(T-T_{0}\right) \\
& q_{r}=\varepsilon \sigma\left(T^{4}-T_{0}{ }^{4}\right)
\end{aligned}
$$

where $T_{0}\left(25^{\circ} \mathrm{C}\right)$ is the room temperature, $\varepsilon(0.6)$ is the emissivity, $\sigma\left(5.67 \times 10^{-8} W \cdot m^{-2} \cdot K^{-4}\right)$ is the Stefan-Boltzmann constant and $h$ $\left(15 \mathrm{~W} \cdot \mathrm{m}^{-2} \cdot \mathrm{K}^{-1}\right)$ is the natural convective heat coefficient.

\subsection{Thermophysical properties}

The material properties were considered temperature dependent for each of the steels evaluated. The heat capacity and thermal conductivity are presented in Figures 2 and 3 respectively. Due to density of the steels has only a small variation at the interval until melting, it was established as a constant value of $7800 \mathrm{~kg} . \mathrm{m}^{-3}$.

\subsection{Model for prediction of maximum hardness at the $H A Z$}

The maximum hardness in the welded region of a metal is one of the most important parameter to estimate the occurrence of low-temperature crack and it is a measured of weldability of the steels. Thus, an attempt to predict the maximum HAZ hardness of the T/P23 and T/P24 steels was made in this work using the model proposed by Yurioka et al. ${ }^{12}$. The model for prediction of maximum hardness of the HAZ use as an 


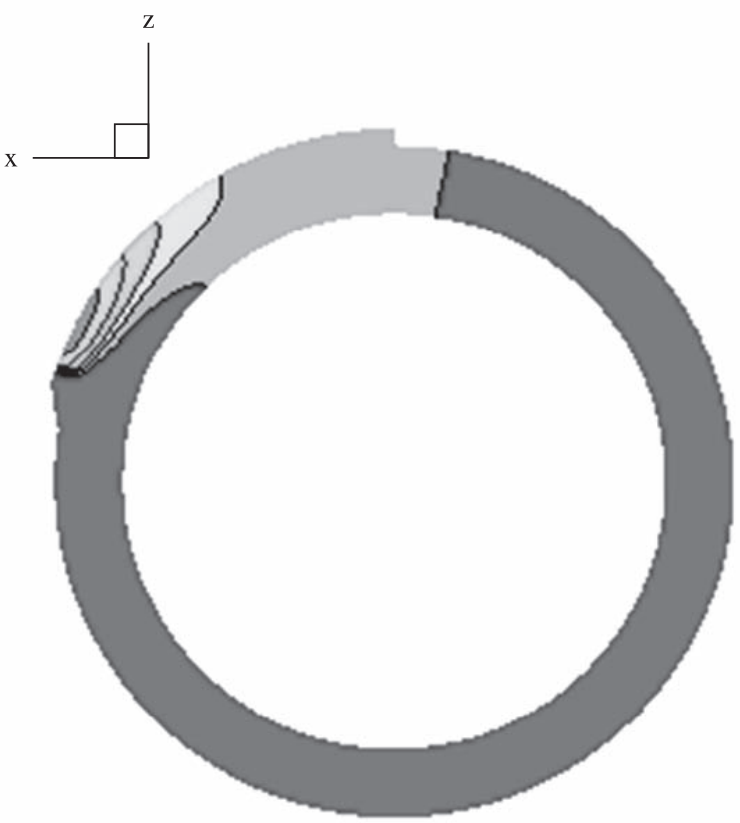

(a)

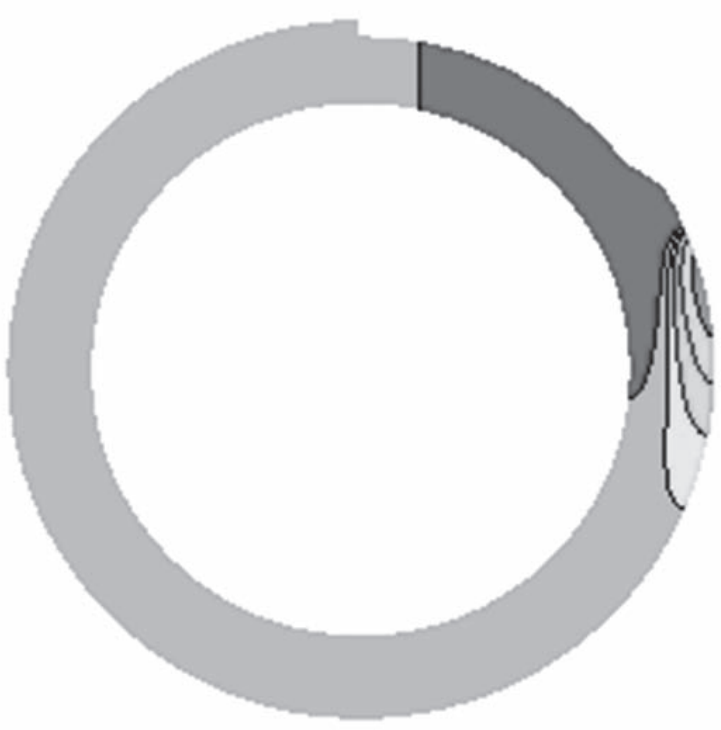

(c)
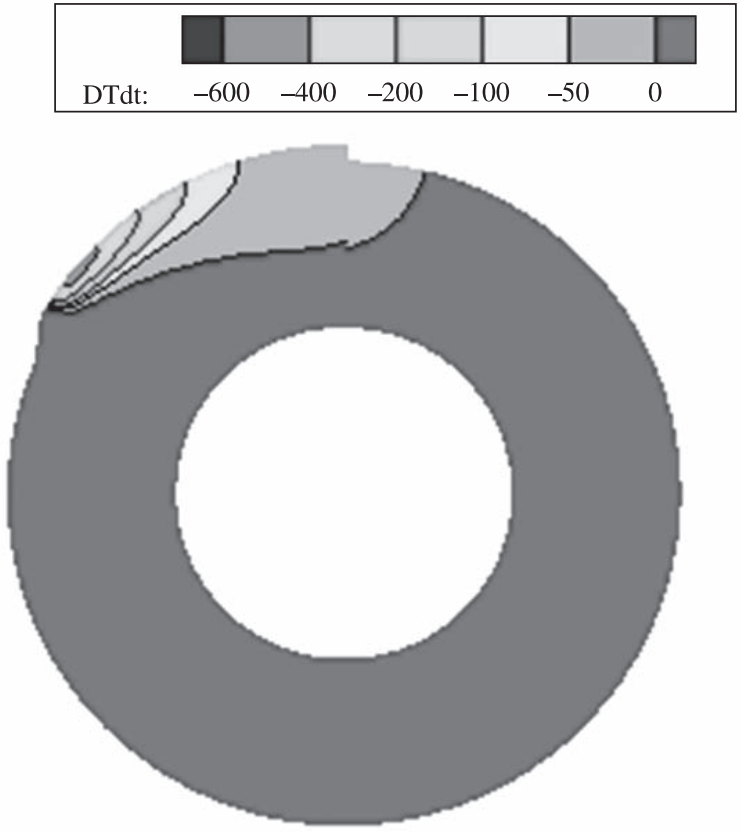

(b)

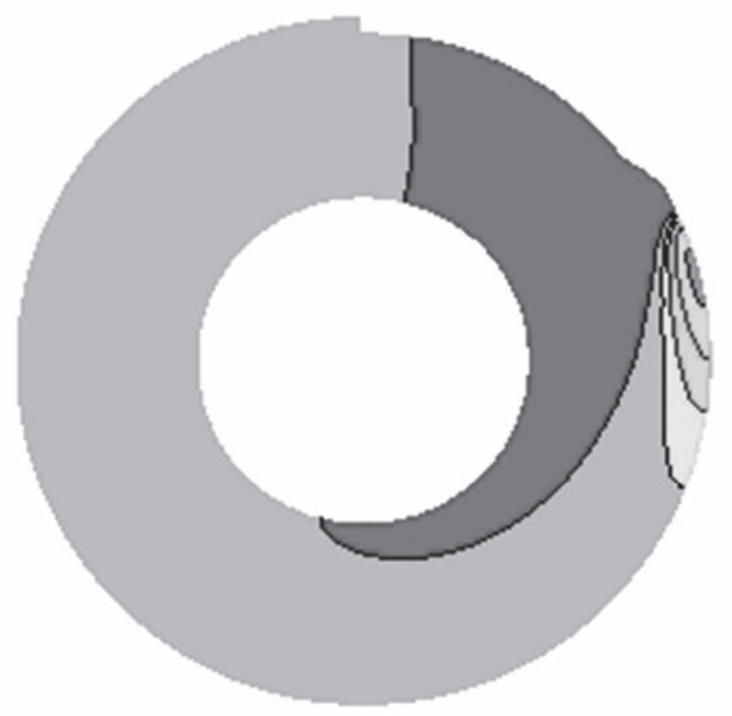

(d)

Figure 7. Predicted temporal and spatial distributions of cooling rates for $0.5 \mathrm{~kJ} \cdot \mathrm{mm}^{-1}$ heat input and its effect on 10 and $25 \mathrm{~mm}$ workpiece thickness $\left({ }^{\circ} \mathrm{C} / \mathrm{s}\right)$ for same time steps.

index the concept of the equivalent carbon and is, therefore, dependent of the chemical composition of the steels. Besides of the steel chemical composition, the model also require the knowledge of the HAZ cooling time between 800 and $500{ }^{\circ} \mathrm{C}\left(t_{8 / 5}\right.$-cooling time $)$. Thus, Equation 6 was used to predict the maximum hardness of the HAZ.

$$
H v=\left(\frac{H_{M}+H_{B}}{2}\right)-\left(\frac{H_{M}-H_{B}}{2.2}\right) \cdot \arctan (X)
$$

In the Equation 6, $H_{v}$ is the Vickers hardness and,

$$
X=4\left(\frac{\log \left(t_{8 / 5} / t_{M}\right)}{\log \left(t_{B} / t_{M}\right)}\right)-2
$$

Parameters $t_{M}$ and $H_{M}$ are related to the time for formation of $100 \%$ of martensite and its hardness respectively, while parameters $t_{B}$ and $H_{B}$ are related to the time for formation of $100 \%$ of bainite and its hardness respectively. Equations 8 to 11 defines the parameters $t_{M}, H_{M}, t_{B}$ and $H_{B}$ respectively, which are dependents of the steel chemical composition.

$$
\begin{aligned}
& t_{M}=\exp \left(10.6 C E_{I}-4.8\right) \\
& H_{M}=884 C\left(1-0.3 C^{2}\right)+294 \\
& t_{B}=\exp \left(6.2 C E_{I I I}+0.74\right) \\
& H_{B}=145+130 \tanh \left(2.65 C E_{I I}-0.69\right)
\end{aligned}
$$




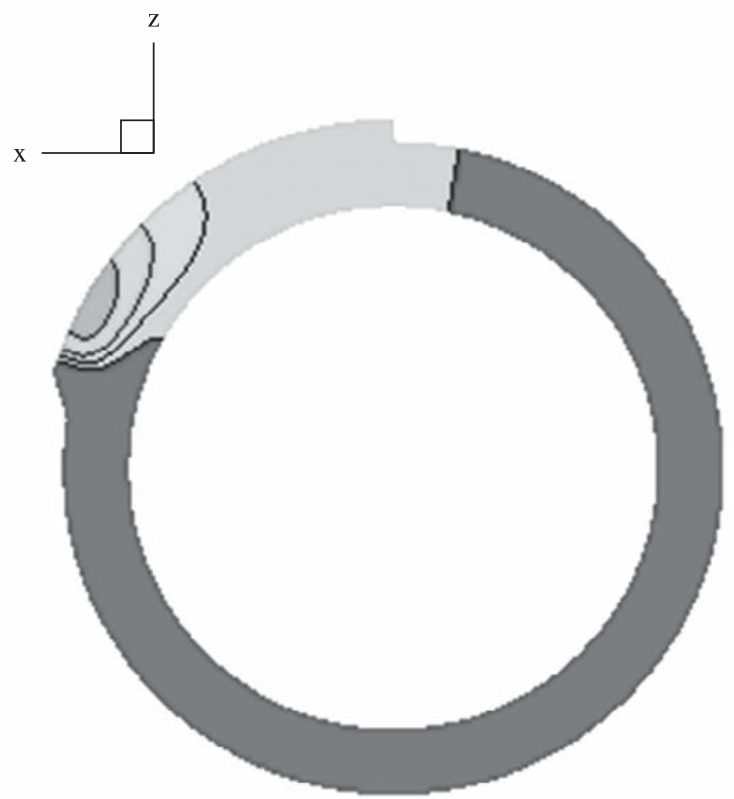

(a)

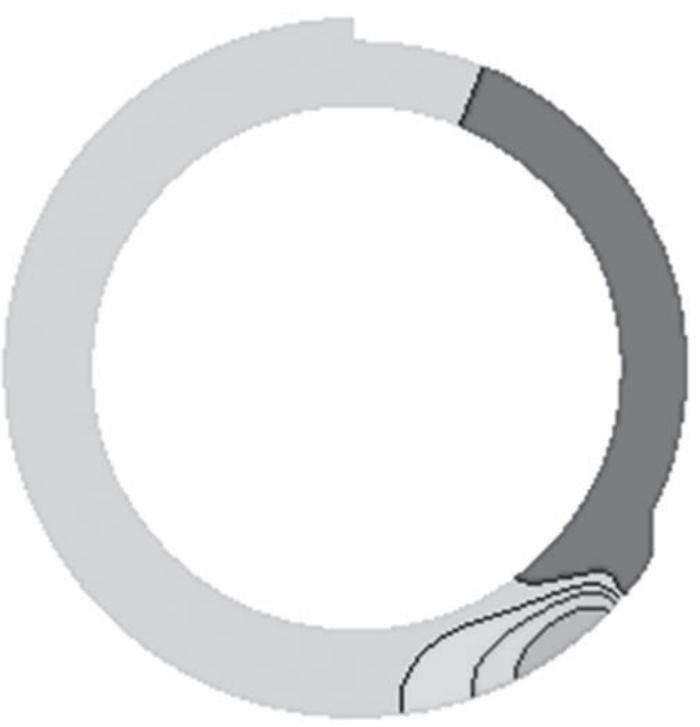

(c)
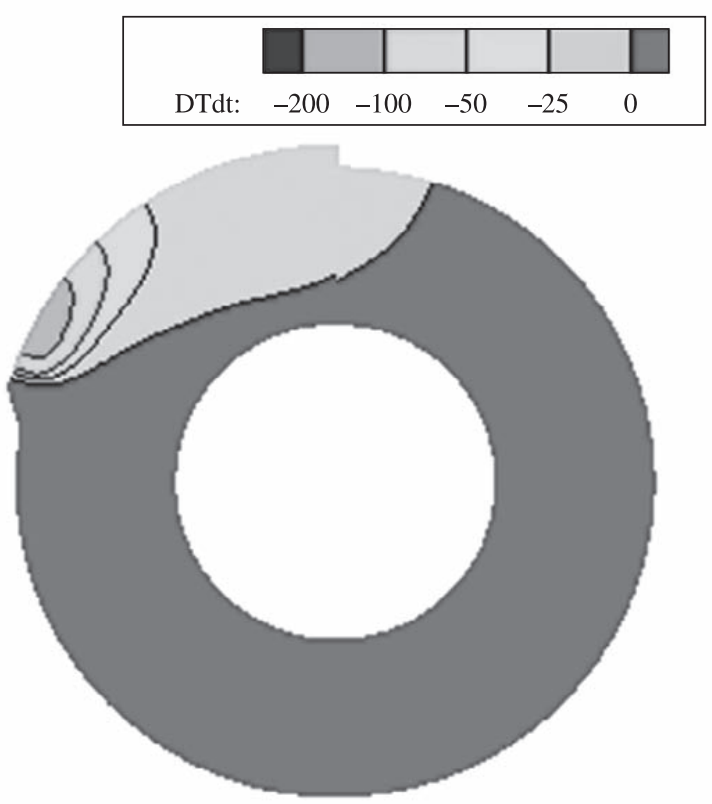

(b)

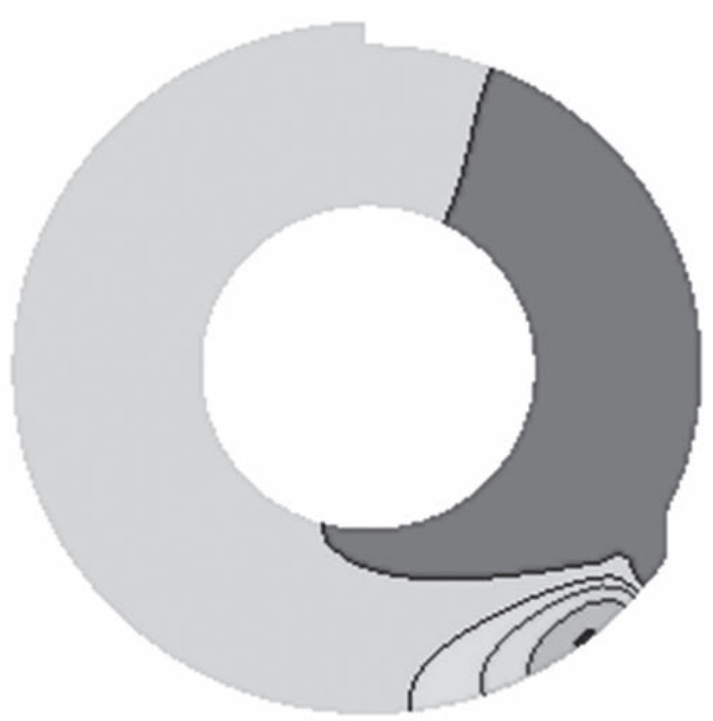

(d)

Figure 8. Predicted temporal and spatial distributions of cooling rates for $1.0 \mathrm{~kJ} \cdot \mathrm{mm}^{-1}$ heat input and its effect on 10 and $25 \mathrm{~mm}$ workpiece thickness $\left({ }^{\circ} \mathrm{C} / \mathrm{s}\right)$ for same time steps.

where,

$$
C E_{I}=C+\frac{S i}{24}+\frac{M n}{6}+\frac{C u}{15}+\frac{N i}{12}+\frac{M o}{4}+\frac{C r(1-0.16 \sqrt{C r})}{8}+f(B) *
$$

$* f(B)$ is a dependent function of the B content present at the steel.

$$
\begin{aligned}
& C E_{I I}=C+\frac{S i}{24}+\frac{M n}{5}+\frac{C u}{10}+\frac{N i}{18}+\frac{C r}{5}+\frac{M o}{2.5}+\frac{V}{5}+\frac{N b}{3} \\
& C E_{I I I}=C+\frac{M n}{3.6}+\frac{C u}{20}+\frac{N i}{9}+\frac{C r}{5}+\frac{M o}{4}
\end{aligned}
$$

\section{Results and Discussion}

\subsection{Double-ellipsoid model parameters}

As previously mentioned, the double-ellipsoid model presents good agreement with experimental data for welding process simulation in order to estimate the 800 to $500{ }^{\circ} \mathrm{C}$ cooling time $\left(t_{8 / 5}\right)^{11}$. The numerical results obtained in this work showed a good agreement with the literature as will be seen in the next sections and the central point for this was the good parameters adjustment of the doubleellipsoid model (Equations 2 and 3). The results obtained for these parameters, together with the respective welding parameters (Table 2), 


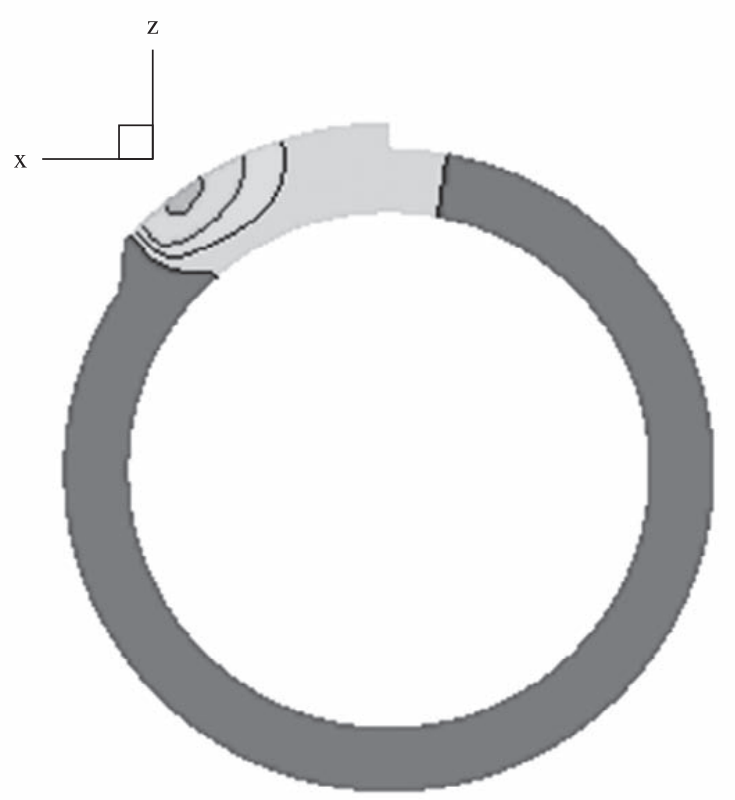

(a)

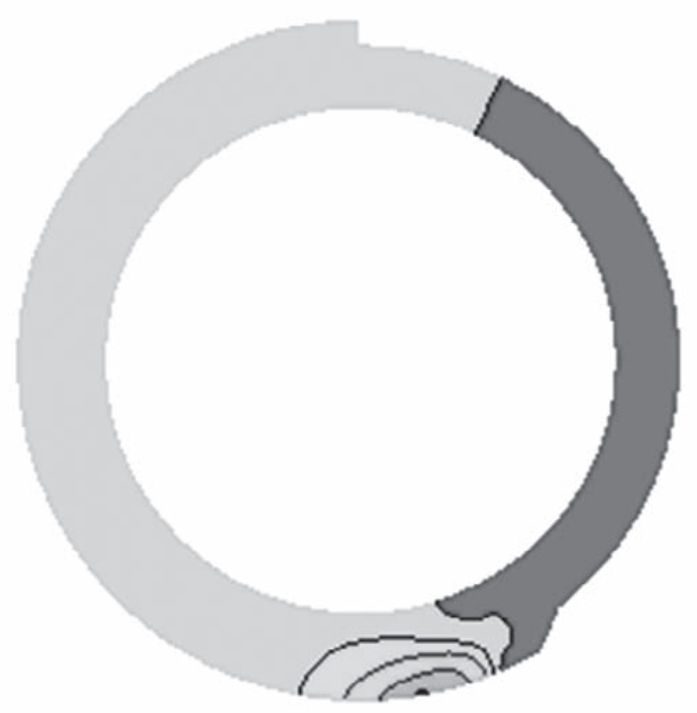

(c)
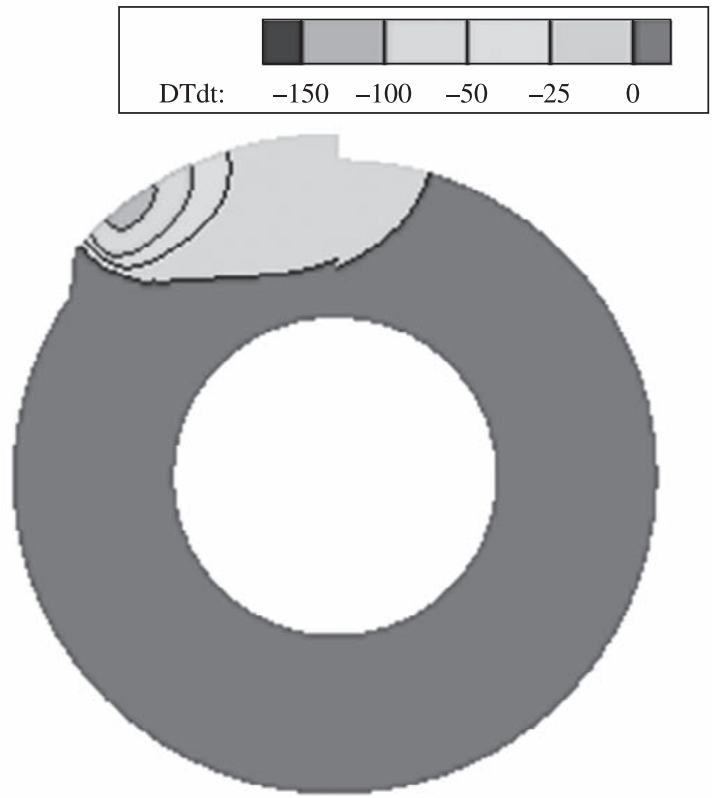

(b)

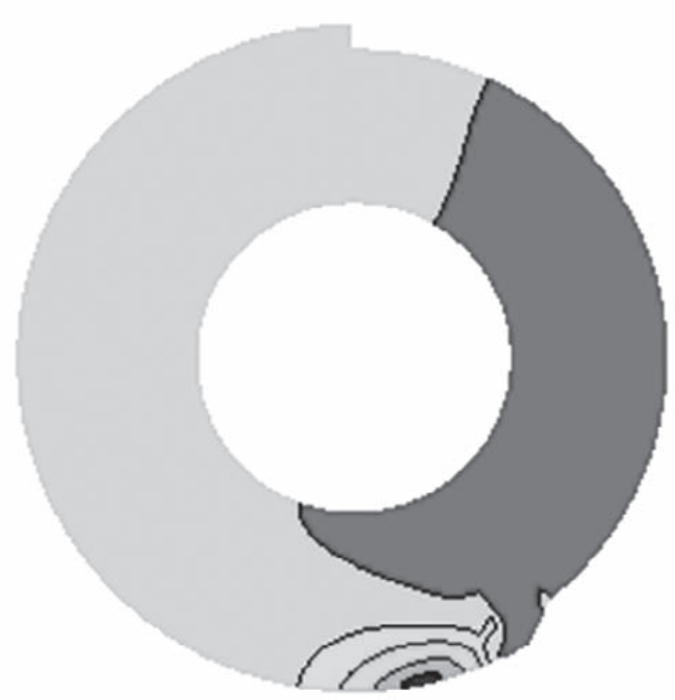

(d)

Figure 9. Predicted temporal and spatial distributions of cooling rates for $1.5 \mathrm{~kJ} . \mathrm{mm}^{-1}$ heat input and its effect on 10 and $25 \mathrm{~mm}$ workpiece thickness $\left({ }^{\circ} \mathrm{C} / \mathrm{s}\right)$ for same time steps.

are shown in the Table 3. Besides, the weld thermal efficiency $\eta$, was considered as unit and the factors $f f$ and $f r$ of the double-ellipsoid model as 0.8 and 1.2 respectively.

\subsection{General results and model validation}

Figure $4 \mathrm{a}$ corresponds to the 3D general result from the welding numerical simulation carried out in this work where can be seen the weld bead and the temperature field. Figures $4 \mathrm{~b}$ and $4 \mathrm{c}$ are simulated and experimental results showing good agreement and validate the model and implementations carried out in this investigation.

\subsection{Temperature distribution}

Figures 5 and 6 show the effect of thickness on the temperature distributions for heat input of $1.0 \mathrm{~kJ} \cdot \mathrm{mm}^{-1}$. The (a-d) sequence in the
Figures 5 and 6 show the results for the temperature distribution for the welding evolution conditions with time along of the centerline of the $10 \mathrm{~mm}$ (T23 and T24) and $25 \mathrm{~mm}$ (P23 and P24) workpiece respectively. As expected, as the thickness increases the effect the temperature distribution is more concentrated around the fusion zone and HAZ and higher thermal gradients are observed in these cases.

\subsection{Heat input effects on cooling rates}

Figures 7 to 11 shows the heat input effects on cooling rates in some selected stages during welding simulation. Besides of the heat input influence, a direct comparison between 10 and $25 \mathrm{~mm}$ worpice cooling rates was also carried out. It can be seen that higher heat input lead to lower cooling rates for all evaluated workpiece thickness (10 and $25 \mathrm{~mm}$ ). In the same way, higher cooling rates were also 


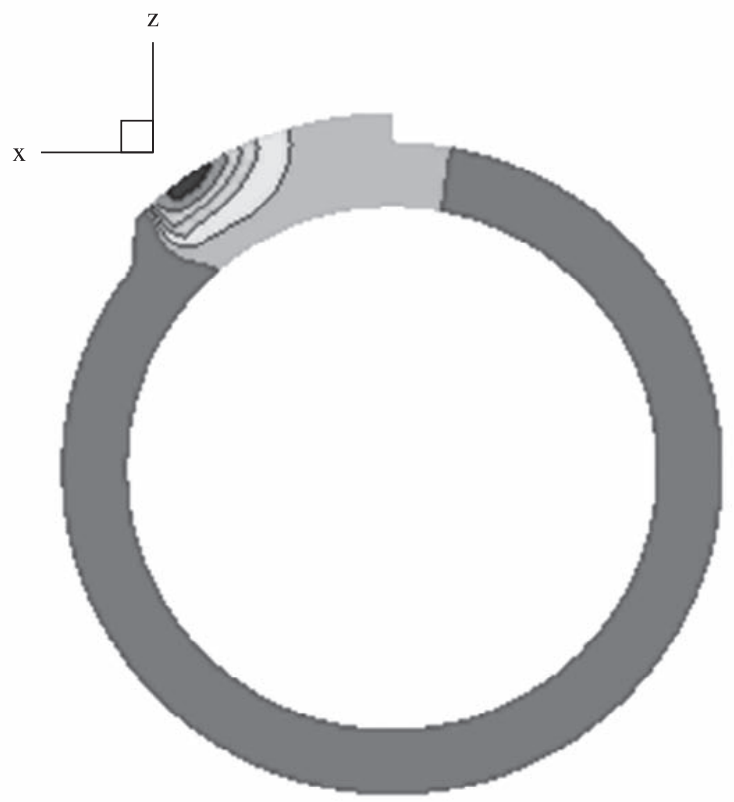

(a)

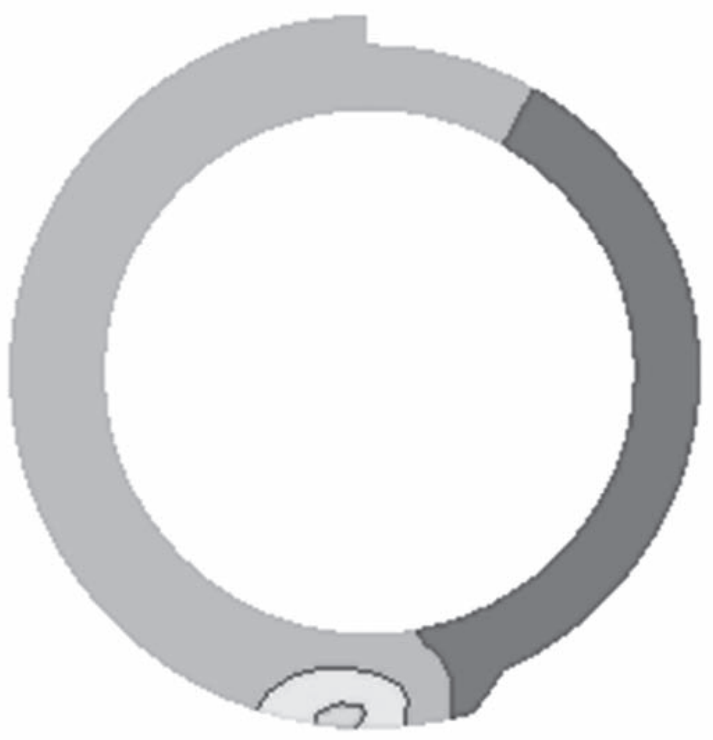

(c)

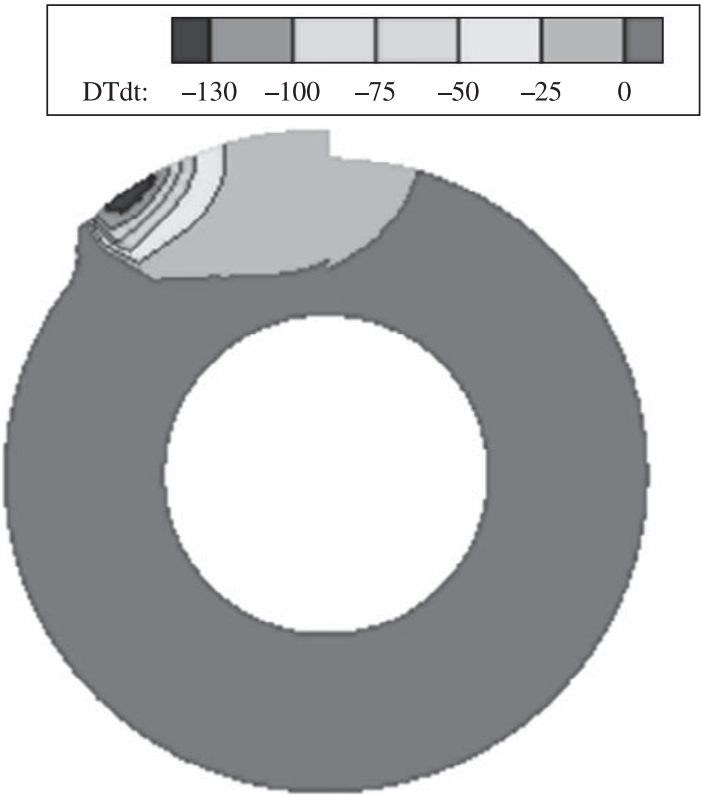

(b)

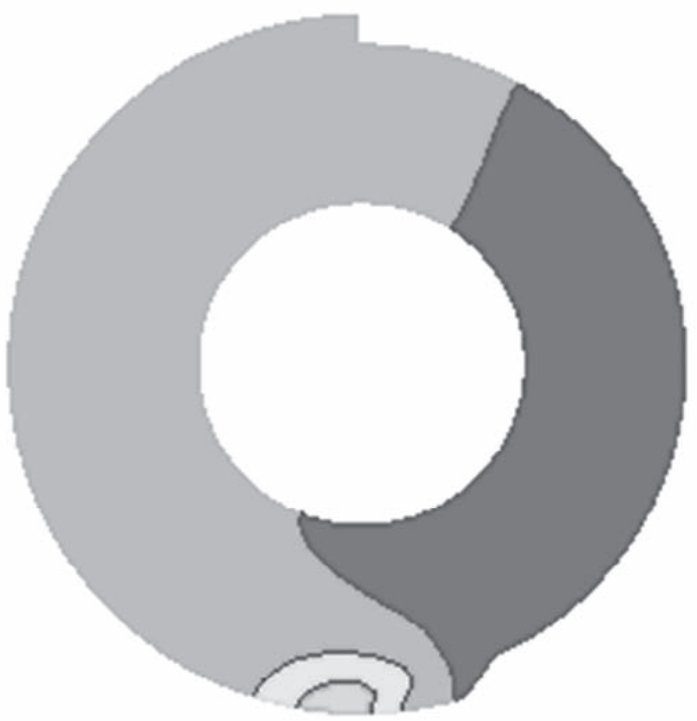

(d)

Figure 10. Predicted temporal and spatial distributions of cooling rates for $2.0 \mathrm{~kJ} \cdot \mathrm{mm}^{-1}$ heat input and its effect on 10 and $25 \mathrm{~mm}$ workpiece thickness $\left({ }^{\circ} \mathrm{C} / \mathrm{s}\right)$ for same time steps.

observed when compared the $25 \mathrm{~mm}$ thickness workpiece to $10 \mathrm{~mm}$ thickness workpiece. These differences becomes more pronounced as the heat input is increased. These results will have a direct influence on the steel microstructural transformation during its welding and, therefore, on its mechanical properties. This subject will be presented and discussed in the next sections.

\subsection{Heat input and thickness influence on the continuous cooling curves}

The influence of heat input and workpiece thickness on the continuous cooling curves which affects the transformations that take places at the HAZ of the T/P23 and T/P24 steels during continuous cooling were investigated. The maximum hardness in the HAZ was estimated where temperature peak reached $1300{ }^{\circ} \mathrm{C}$ using the model proposed by Yurioka et al. ${ }^{2}$. Besides of $t_{8 / 5}$-cooling time, steel chemical composition is also necessary in order to estimate its hardness. The simulated $t_{8 / 5}$-cooling times and the hardness estimated by the model are show in the Table 4 . The chemicals compositions used to evaluate the hardness of the T/P23 and T/P24 steels were choosen based on values usually presented on the literature and shown in Table 5. For the sake of simplicity, it was considered that the T23 (10 mm) and the P23 (25 mm) steels had the same chemical composition with analogous procedure adopted for the T24 (10 mm) and P24 $(25 \mathrm{~mm})$ steels. A brief commentary here about the model is 


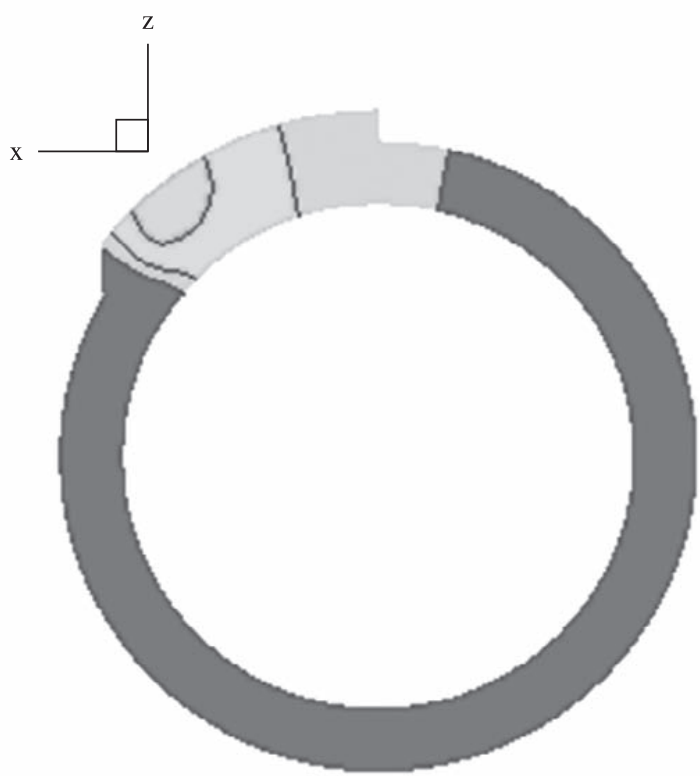

(a)

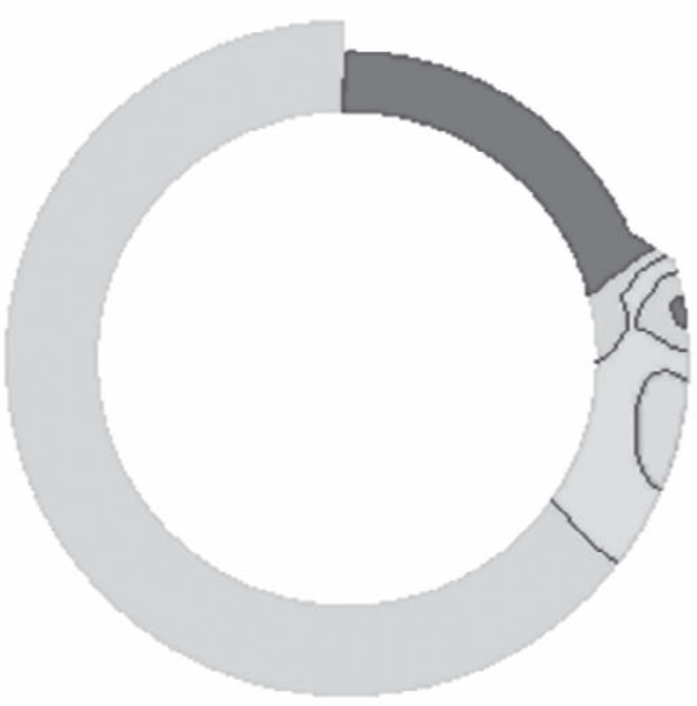

(c)

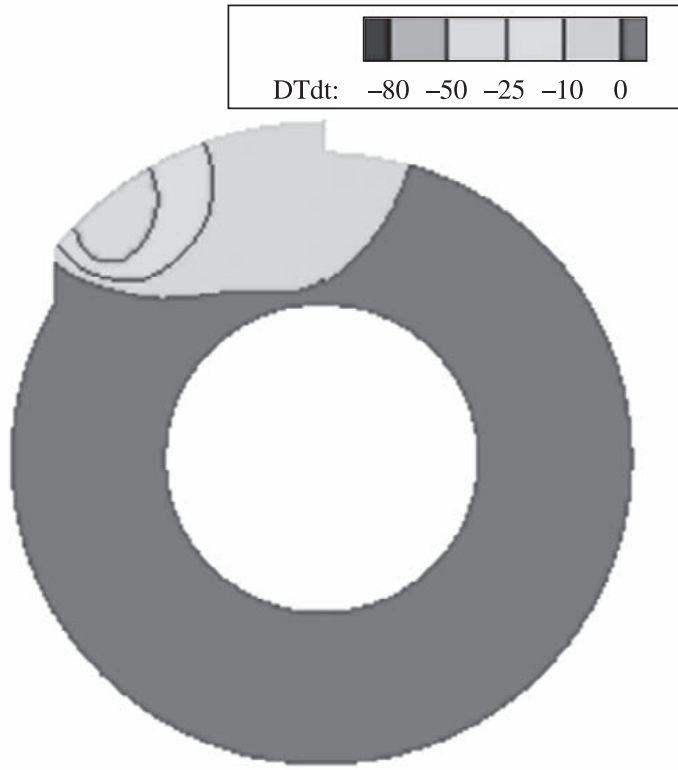

(b)

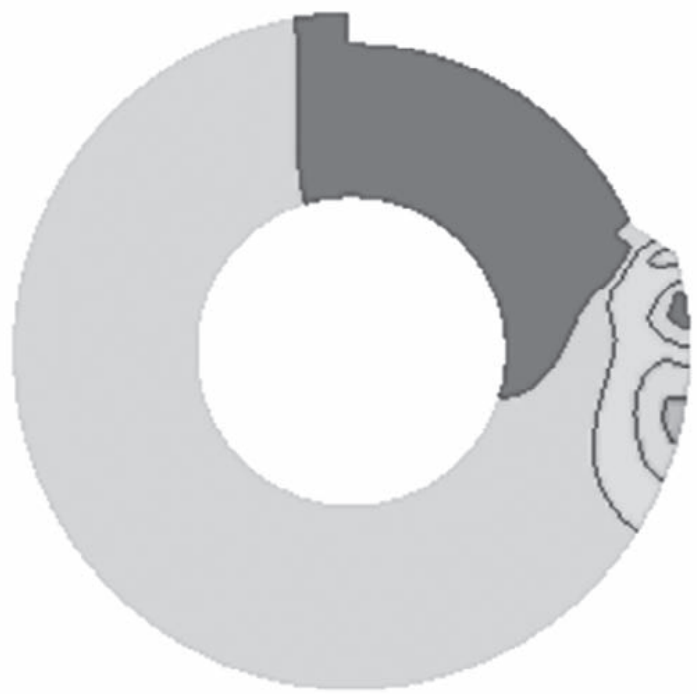

(d)

Figure 11. Predicted temporal and spatial distributions of cooling rates for $2.5 \mathrm{~kJ} . \mathrm{mm}^{-1}$ heat input and its effect on 10 and $25 \mathrm{~mm}$ workpiece thickness $\left({ }^{\circ} \mathrm{C} / \mathrm{s}\right)$ for same time steps.

that it does not consider the effects of $\mathrm{W}, \mathrm{Ti}$ and $\mathrm{Al}$ in its formulation. $\mathrm{Ti}$ and $\mathrm{Al}$ are presents in very low content in the steels and thus, was considered that their effects is negligible on the hardness, whereas the $\mathrm{W}$ content is significant at the T/P23 steel. In this case, in order to estimate the T/P23 hardness, an attempt was made by substituting Mo for W at the Yurioka's model. It can be justified by considering that both elements are equivalents chemically and exhibits similar effect on several metallurgical reactions of the steels ${ }^{13}$.

Figures 12 and 13 show the heat input effects on the continuous cooling curves for the T23 and T24 steels respectively. Higher hardness are achieved at the HAZ when cooling rates increases or lower heat input are imposed since that more martensite is formed. Due its poorer properties, the transformation into ferrite must be avoid, consequently very high heat inputs are inappropriate. These results are in agreement with those presented at literature ${ }^{4}$ which propose an heat input between 1.5 and $2.5 \mathrm{~kJ} . \mathrm{mm}^{-1}$ for thin-walled tubes. Heat input between $1.5 \mathrm{~kJ} . \mathrm{mm}^{-1}$ and $2.5 \mathrm{~kJ} . \mathrm{mm}^{-1}$ can assurance at the same time an HAZ hardness lower than $350 \mathrm{HV}$ in order to avoid preheating and PWHT and good mechanical properties respectively.

Figures 14 to 23 shows the effect of the workpiece thickness on the cooling curves during transformation under continuos cooling of the steels evaluated using an heat input from 0.5 to $2.5 \mathrm{~kJ} . \mathrm{mm}^{-1}$. Greater wall thickness shift the cooling curve for left, due to higher cooling rates in all cases evaluated which results in the increase of the HAZ hardness since that more martensite is obtained. If the limit of hardness of $350 \mathrm{HV}$ for application in power generation must be observed, then a preheating must be carried out in order to 
Table 4. Heat input and thickness effects on simulated $t_{8 / 5}$-cooling time and hardness of the T/P23 and T/P24 steels.

\begin{tabular}{|c|c|c|c|c|}
\hline \multirow[t]{2}{*}{$\begin{array}{l}\text { Heat input } \\
\left(\mathrm{kJ} \cdot \mathrm{mm}^{-1}\right)\end{array}$} & \multirow[t]{2}{*}{$\begin{array}{c}\text { Thickness } \\
\text { (mm) }\end{array}$} & \multirow[t]{2}{*}{$\begin{array}{c}t_{8 / 5} \\
\text { (simulated) } \\
(\mathrm{s})\end{array}$} & \multicolumn{2}{|c|}{$\begin{array}{c}\text { Hardness } \\
\text { (Yurioka's model) } \\
(\mathrm{Hv})\end{array}$} \\
\hline & & & T/P23 & $\mathrm{T} / \mathrm{P} 24$ \\
\hline \multirow{2}{*}{0.5} & 10 & 3 & 356 & 354 \\
\hline & 25 & 2 & 357 & 355 \\
\hline \multirow{2}{*}{1.0} & 10 & 11 & 354 & 348 \\
\hline & 25 & 4 & 356 & 352 \\
\hline \multirow{2}{*}{1.5} & 10 & 22 & 351 & 341 \\
\hline & 25 & 6 & 355 & 351 \\
\hline \multirow{2}{*}{2.0} & 10 & 35 & 349 & 333 \\
\hline & 25 & 9 & 355 & 349 \\
\hline \multirow{2}{*}{2.5} & 10 & 49 & 346 & 324 \\
\hline & 25 & 12 & 354 & 347 \\
\hline 4.0 & 10 & 83 & 339 & 305 \\
\hline
\end{tabular}

Table 5. T/P23 and T/P24 steels chemical compostion used for simulation.

\begin{tabular}{clc}
\hline (\%) weight & $\mathrm{T} / \mathrm{P} 23$ & $\mathrm{~T} / \mathrm{P} 24$ \\
\hline $\mathrm{C}$ & 0.060 & 0.060 \\
$\mathrm{Si}$ & 0.220 & 0.290 \\
$\mathrm{P}$ & 0.014 & 0.014 \\
$\mathrm{~S}$ & 0.002 & 0.003 \\
$\mathrm{Mn}$ & 0.470 & 0.410 \\
$\mathrm{Cr}$ & 2.05 & 2.31 \\
$\mathrm{Mo}$ & 0.08 & 0.95 \\
$\mathrm{~V}$ & 0.230 & 0.228 \\
$\mathrm{~W}$ & 1.510 & - \\
$\mathrm{Al}$ & 0.017 & 0.010 \\
$\mathrm{~B}$ & 0.0019 & 0.0046 \\
$\mathrm{~N}$ & 0.009 & 0.0080 \\
$\mathrm{Nb}$ & 0.050 & - \\
$\mathrm{Ti}$ & - & 0.079 \\
\hline
\end{tabular}

diminish the resulting hardness. This conclusion is in compliance with literature ${ }^{4,8,9}$ which suggest an heat input between 1.0 and $3.5 \mathrm{~kJ} . \mathrm{mm}^{-1}$ for the welding of P23 and P24 steels besides of fact that a preheating must be usually realized in thick-walled pipes in order to obtain good properties for the weldment.

\subsection{Preheating effects}

According with literature ${ }^{8,9}$, the welding of thin-walled tubes, in this case T23 and T24, can be performed with or without preheating up to about $200{ }^{\circ} \mathrm{C}$, since a slight difference in hardness has been reported. Therefore, two preheating temperatures 100 and $200{ }^{\circ} \mathrm{C}$ and the heat input of $1.0 \mathrm{~kJ} \cdot \mathrm{mm}^{-1}$ were investigated in this work. The results for the simulated $t_{8 / 5}$-cooling times using preheating and the hardness obtained are in the Table 6, whereas the steels chemical composition in the Table 5. Figures 24 and 25 show the

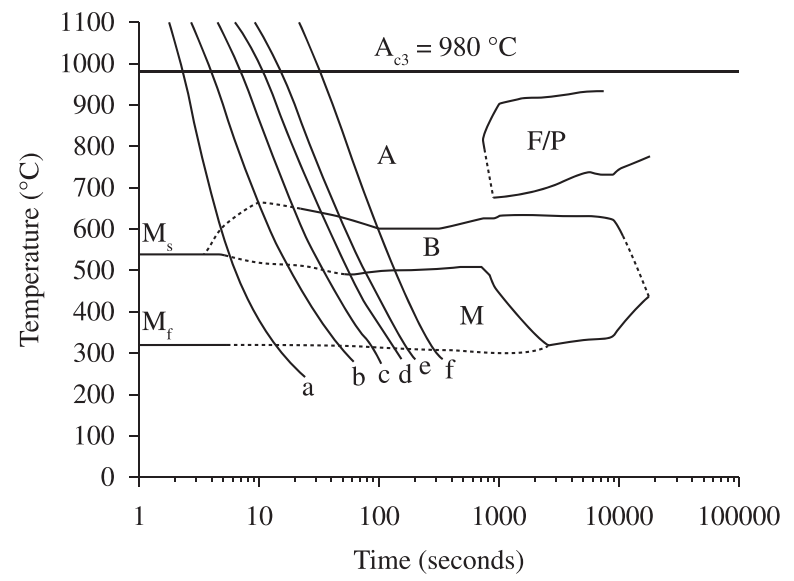
(a) $0.5 \mathrm{~kJ} \cdot \mathrm{mm}^{-1}-356 \mathrm{HV}$
(b) $1.0 \mathrm{~kJ} \cdot \mathrm{mm}^{-1}-354 \mathrm{HV}$
(c) $1.5 \mathrm{~kJ} \cdot \mathrm{mm}^{-1}-351 \mathrm{HV}$
(d) $2.0 \mathrm{~kJ} \cdot \mathrm{mm}^{-1}-349 \mathrm{HV}$
(e) $2.5 \mathrm{~kJ} \cdot \mathrm{mm}^{-1}-346 \mathrm{HV}$
(f) $4.0 \mathrm{~kJ} \cdot \mathrm{mm}^{-1}-339 \mathrm{HV}$

Figure 12. Calculated effect of heat input on HAZ continuous cooling of T23 steel.

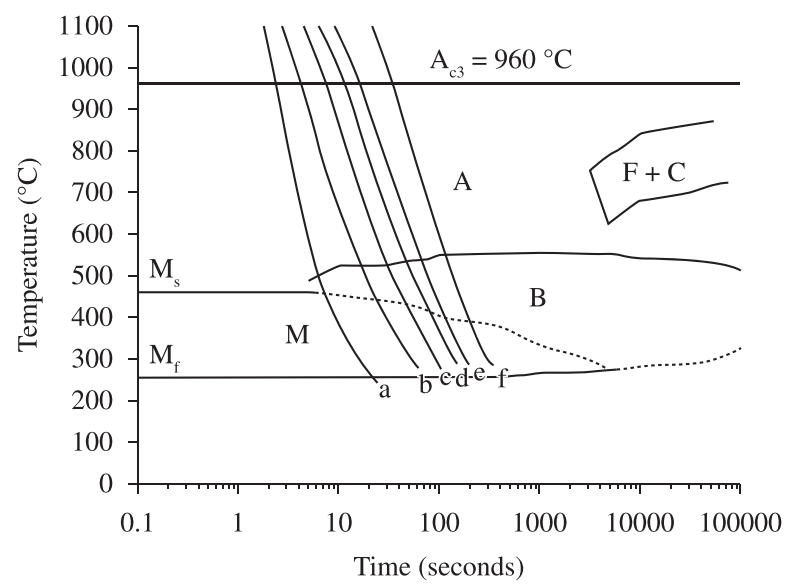
(a) $0.5 \mathrm{~kJ} \cdot \mathrm{mm}^{-1}-354 \mathrm{HV}$
(b) $1.0 \mathrm{~kJ} \cdot \mathrm{mm}^{-1}-333 \mathrm{HV}$
(c) $1.5 \mathrm{~kJ} \cdot \mathrm{mm}^{-1}-348 \mathrm{HV}$
(d) $2.0 \mathrm{~kJ} \cdot \mathrm{mm}^{-1}-324 \mathrm{HV}$
(e) $2.5 \mathrm{~kJ} \cdot \mathrm{mm}^{-1}-341 \mathrm{HV}$
(f) $4.0 \mathrm{~kJ} \cdot \mathrm{mm}^{-1}-305 \mathrm{HV}$

Figure 13. Calculated effect of heat input on HAZ continuous cooling of T24 steel.

preheating effects on the cooling curve during transformation under continuous cooling of the T23 and T24 steels respectively. Although the $1.0 \mathrm{~kJ} . \mathrm{mm}^{-1}$ heat input be out of range suggested for welding of the T23 and T24 steels as previously discussed, its choose was made aiming to confirm that preheating until $200{ }^{\circ} \mathrm{C}$ presents a small effects on the T23 and T24 steels hardness. Thus, more elevated preheating temperature will be necessary in order to promote a significant hardness reduction or greater heat input $\left(>1.0 \mathrm{~kJ} . \mathrm{mm}^{-1}\right)$ must be used in the welding of T23 and T24 steels. These results can be advantageously used in the welding of the T23 and T24 steels when are utilized greater welding energy $\left(>1.0 \mathrm{~kJ} . \mathrm{mm}^{-1}\right)$ since the effects of preheating until $200{ }^{\circ} \mathrm{C}$ do not modify considerably their hardness. This conclusion becomes the use of T23 and T24 steels very attractive since preheating, although useful to improved the welded joint properties, as hardness and toughness, can be difficult to carry out besides of increasing the costs. 


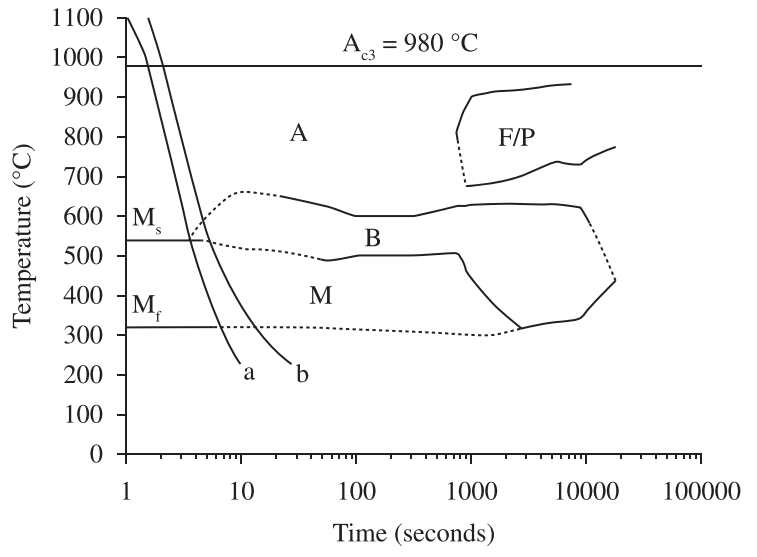

(a) $0.5 \mathrm{~kJ} \cdot \mathrm{mm}^{-1}-25 \mathrm{~mm}-357 \mathrm{HV}$

(b) $0.5 \mathrm{~kJ} \cdot \mathrm{mm}^{-1}-10 \mathrm{~mm}-356 \mathrm{HV}$

Figure 14. Calculated effect of thickness on HAZ continuous cooling of T/P23 steel.

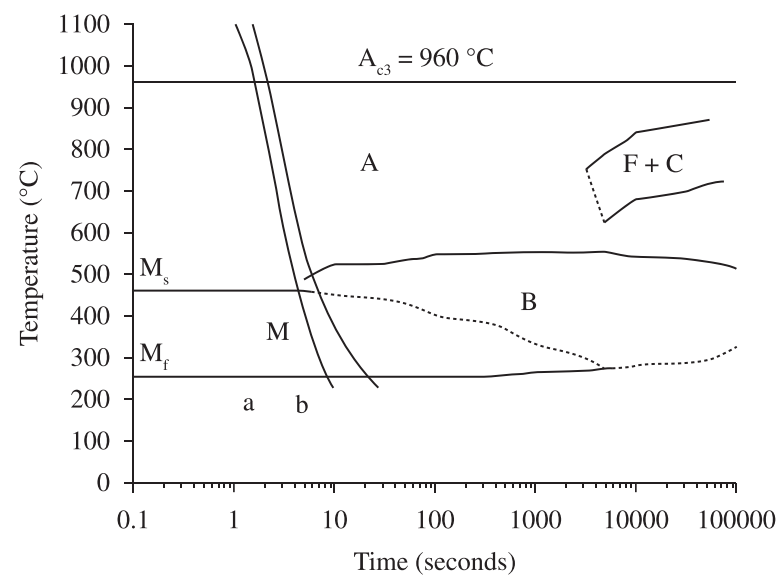

(a) $0.5 \mathrm{~kJ} \cdot \mathrm{mm}^{-1}-25 \mathrm{~mm}-355 \mathrm{HV}$

(b) $0.5 \mathrm{~kJ} \cdot \mathrm{mm}^{-1}-10 \mathrm{~mm}-354 \mathrm{HV}$

Figure 15. Calculated effect of thickness on HAZ continuous cooling of T/P24 steel.

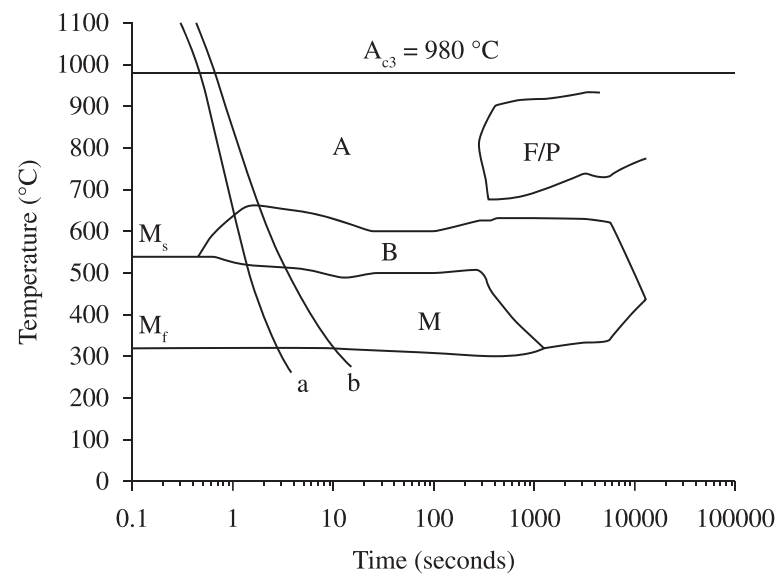

(a) $1.0 \mathrm{~kJ} \cdot \mathrm{mm}^{-1}-25 \mathrm{~mm}-356 \mathrm{HV}$

(b) $1.0 \mathrm{~kJ} \cdot \mathrm{mm}^{-1}-10 \mathrm{~mm}-354 \mathrm{HV}$

Figure 16. Calculated effect of thickness on HAZ continuous cooling of T/P23 steel.

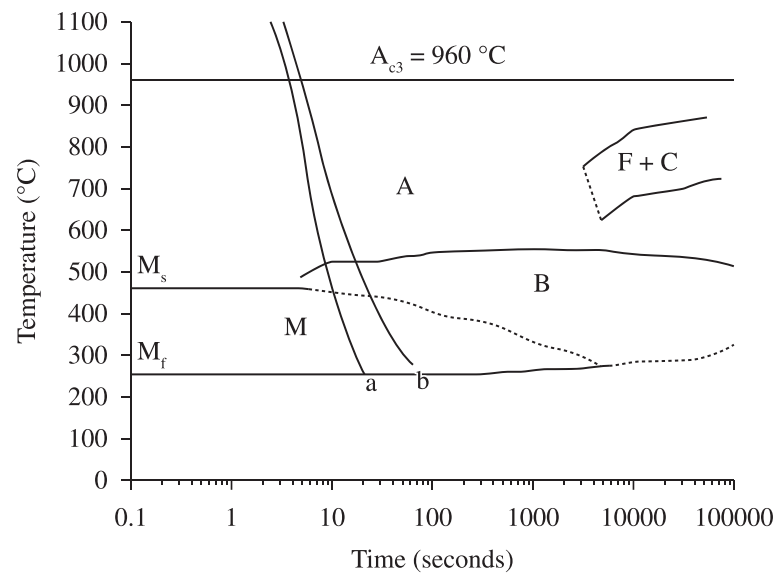

(a) $1.0 \mathrm{~kJ} \cdot \mathrm{mm}^{-1}-25 \mathrm{~mm}-352 \mathrm{HV}$

(b) $1.0 \mathrm{~kJ} \cdot \mathrm{mm}^{-1}-10 \mathrm{~mm}-348 \mathrm{HV}$

Figure 17. Calculated effect of thickness on HAZ continuous cooling of T/P24 steel.

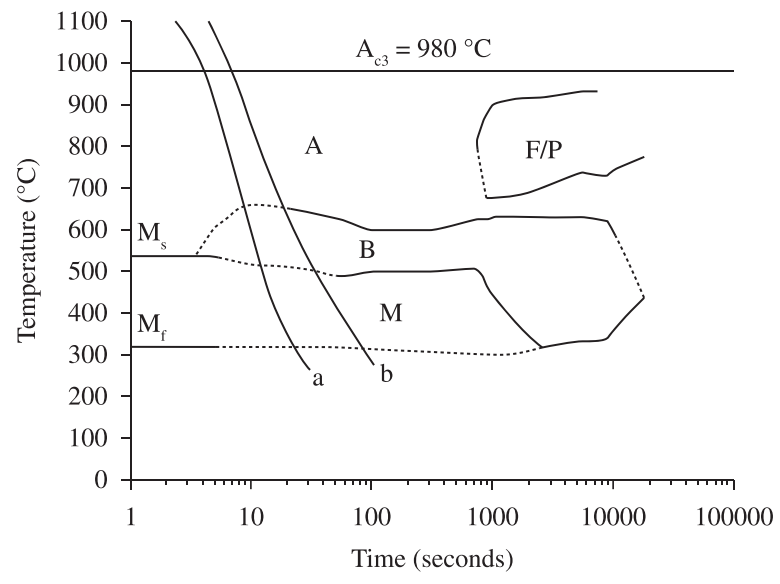

(a) $1.5 \mathrm{~kJ} \cdot \mathrm{mm}^{-1}-25 \mathrm{~mm}-355 \mathrm{HV}$

(b) $1.5 \mathrm{~kJ} \cdot \mathrm{mm}^{-1}-10 \mathrm{~mm}-351 \mathrm{HV}$

Figure 18. Calculated effect of thickness on HAZ continuous cooling of T/P23 steel.

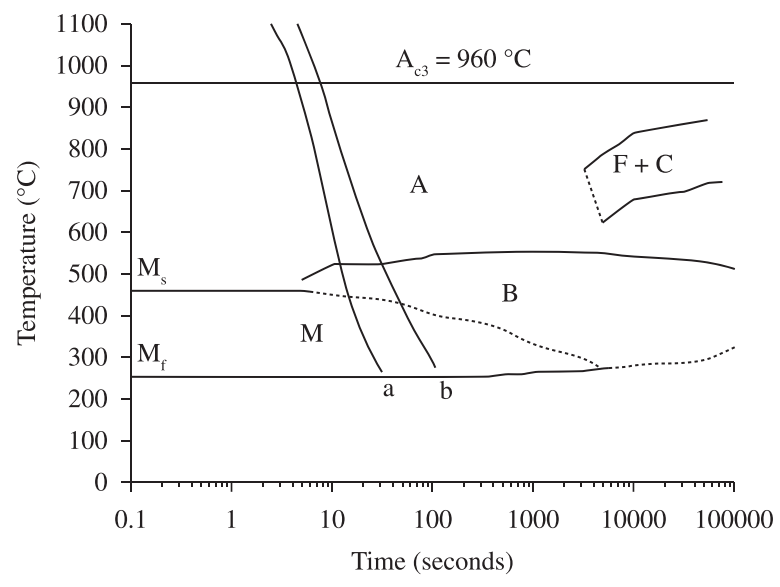

(a) $1.5 \mathrm{~kJ} \cdot \mathrm{mm}^{-1}-25 \mathrm{~mm}-351 \mathrm{HV}$

(b) $1.5 \mathrm{~kJ} \cdot \mathrm{mm}^{-1}-10 \mathrm{~mm}-341 \mathrm{HV}$

Figure 19. Calculated effect of thickness on HAZ continuous cooling of $\mathrm{T} / \mathrm{P} 24$ steel. 


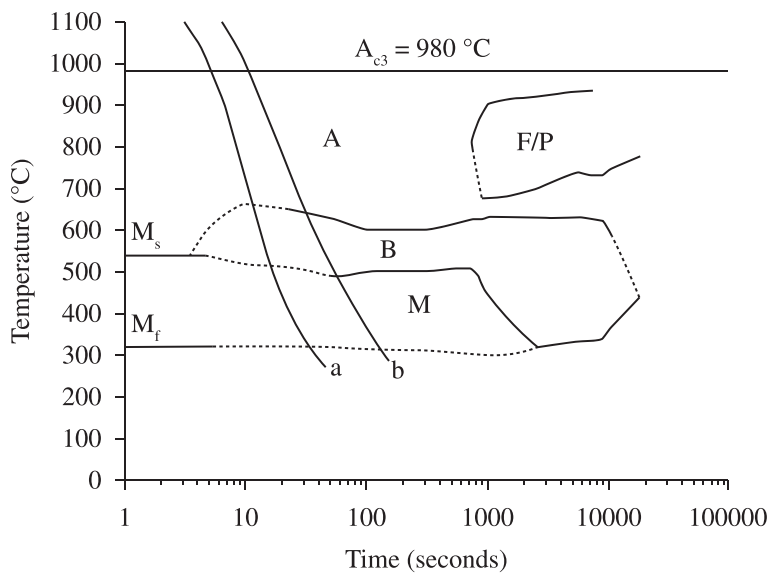

(a) $2.0 \mathrm{~kJ} \cdot \mathrm{mm}^{-1}-25 \mathrm{~mm}-355 \mathrm{HV}$

(b) $2.0 \mathrm{~kJ} \cdot \mathrm{mm}^{-1}-10 \mathrm{~mm}-349 \mathrm{HV}$

Figure 20. Calculated effect of thickness on HAZ continuous cooling of T/P23 steel.

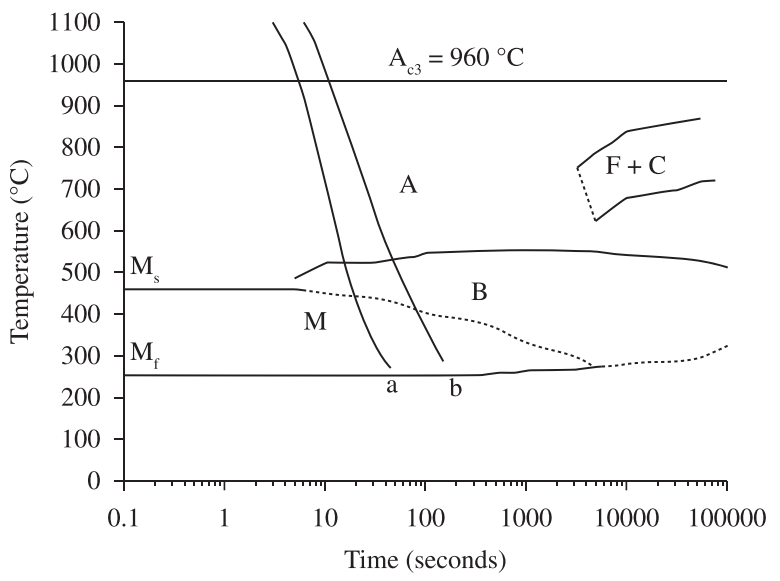

(a) $2.0 \mathrm{~kJ} \cdot \mathrm{mm}^{-1}-25 \mathrm{~mm}-349 \mathrm{HV}$

(b) $2.0 \mathrm{~kJ} \cdot \mathrm{mm}^{-1}-10 \mathrm{~mm}-333 \mathrm{HV}$

Figure 21. Calculated effect of thickness on HAZ continuous cooling of T/P24 steel.

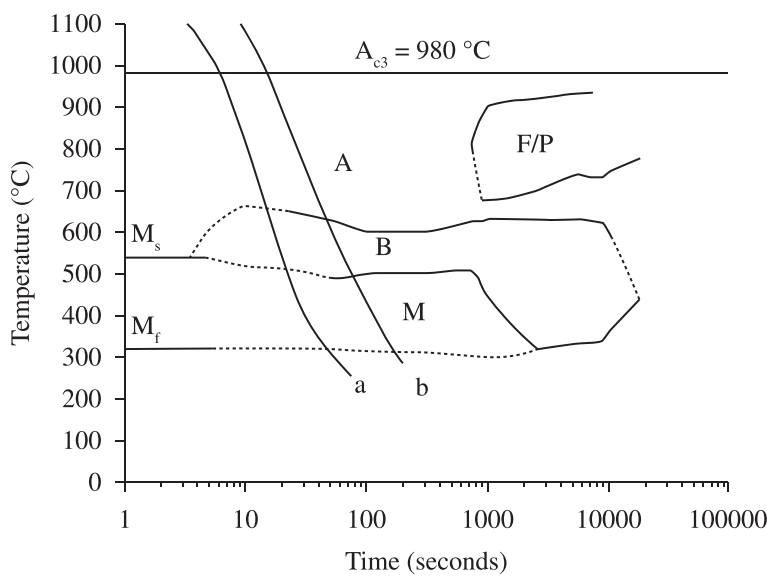

(a) $2.5 \mathrm{~kJ} \cdot \mathrm{mm}^{-1}-25 \mathrm{~mm}-355 \mathrm{HV}$

(b) $2.5 \mathrm{~kJ} \cdot \mathrm{mm}^{-1}-10 \mathrm{~mm}-346 \mathrm{HV}$

Figure 22. Calculated effect of thickness on HAZ continuous cooling of $\mathrm{T} / \mathrm{P} 23$ steel.

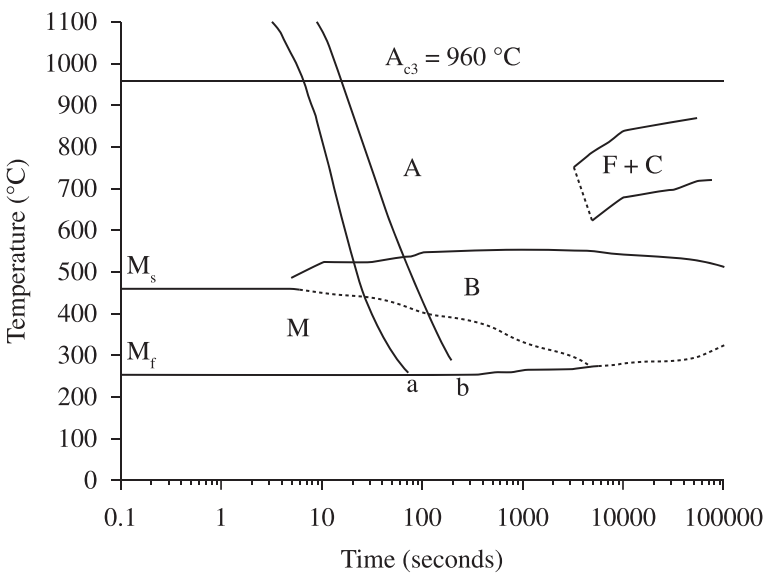

(a) $2.5 \mathrm{~kJ} \cdot \mathrm{mm}^{-1}-25 \mathrm{~mm}-347 \mathrm{HV}$

(b) $2.5 \mathrm{~kJ} \cdot \mathrm{mm}^{-1}-10 \mathrm{~mm}-324 \mathrm{HV}$

Figure 23. Calculated effect of thickness on HAZ continuous cooling of $\mathrm{T} / \mathrm{P} 24$ steel.

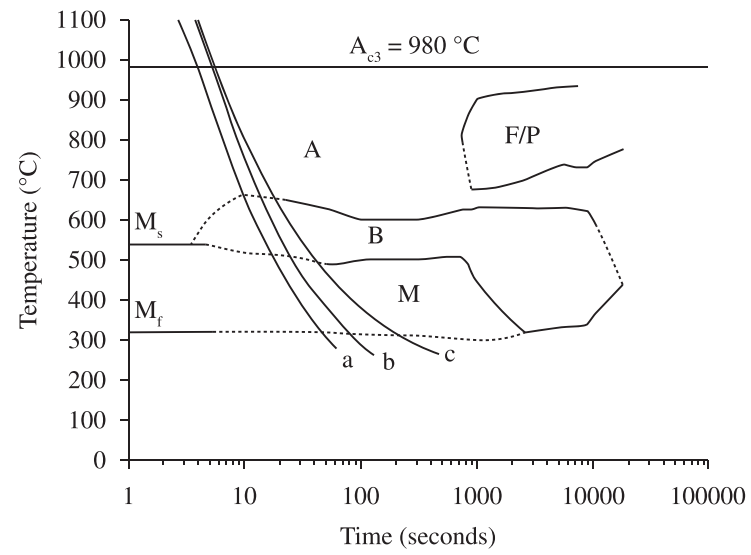

(a) $1.0 \mathrm{~kJ} \cdot \mathrm{mm}^{-1}$ - without preheating - $354 \mathrm{HV}$

(b) $1.0 \mathrm{~kJ} \cdot \mathrm{mm}^{-1}$ - preheating: $100{ }^{\circ} \mathrm{C}-353 \mathrm{HV}$

(c) $1.0 \mathrm{~kJ} \cdot \mathrm{mm}^{-1}$ - preheating: $200{ }^{\circ} \mathrm{C}-350 \mathrm{HV}$

Figure 24. Calculated effect of preheating temperature on HAZ continuous cooling of T23 steel.

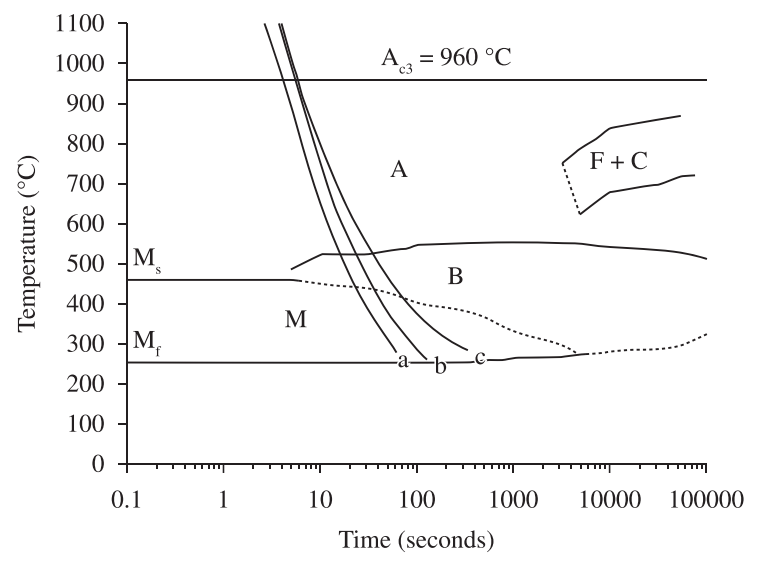
(a) $1.0 \mathrm{~kJ} \cdot \mathrm{mm}^{-1}$ - without preheating - $348 \mathrm{HV}$
(b) $1.0 \mathrm{~kJ} \cdot \mathrm{mm}^{-1}$ - preheating: $100^{\circ} \mathrm{C}-344 \mathrm{HV}$
(c) $1.0 \mathrm{~kJ} \cdot \mathrm{mm}^{-1}$ - preheating: $200{ }^{\circ} \mathrm{C}-335 \mathrm{HV}$

Figure 25. Calculated effect of preheating temperature on HAZ continuous cooling of T24 steel. 
Table 6. Preheating effects on $t_{8 / 5}$-cooling time and hardness of T23 and T24 steels.

\begin{tabular}{ccccc}
\hline Preheating & $\begin{array}{c}t_{8 / 5} \\
(\text { simulated })\end{array}$ & $\begin{array}{c}\text { Heat input } \\
\left(\mathrm{kJ} . \mathrm{mm}^{-1}\right)\end{array}$ & & \multicolumn{2}{c}{ Hardness $(\mathrm{HV})$} \\
\cline { 4 - 5 } & $(\mathrm{s})$ & & $\mathrm{T} 23$ & $\mathrm{~T} 24$ \\
\hline Without & 11 & & 354 & 348 \\
$100{ }^{\circ} \mathrm{C}$ & 17 & 1.0 & 353 & 344 \\
$200{ }^{\circ} \mathrm{C}$ & 31 & & 350 & 335 \\
\hline
\end{tabular}

\section{Conclusions}

A computational code that applies the FVM to solve transport equations was specially developed in order to get a better understanding of the weldability of the low alloy ferritic steels T/P23 and T/P24. The results obtained by the numerical simulation can be summarized as follows:

1. A heat input between 1.5-2.5 kJ.mm ${ }^{-1}$ for welding of T23 and T24 steels can assure an HAZ hardness lower than $350 \mathrm{HV}$ in order to avoid preheating and PWHT and good mechanical properties respectively.

2. Using preheating and a heat input between $1.0-3.5 \mathrm{~kJ}^{-\mathrm{mm}^{-1} \text { at }}$ the welding of P23 and P24 steels can assure an suitable HAZ hardness level and good mechanical properties.

3. The use of preheating until $200{ }^{\circ} \mathrm{C}$ showed a small effect on the cooling curves and, therefore, on the HAZ hardness of T23 and T24 steels. This behaviour makes possible to dispense of preheating during welding of T23 and T24 steels becoming very attractive their use since that preheating, although useful to improve the weldment properties, as hardness and toughness, can be difficult to carry out besides of increasing the costs.

\section{References}

1. Lundin CD, Liu P and Cui Y. A literature review on characteristics of high temperature ferritic Cr-Mo steels and weldments. Welding Research Council Bulletin. 2000; 454:1-36.

2. Vaillant JC, Vandenberghe B, Hahn B, Heuser H and Jochum C. T/P23, 24, 911 and 92: new grades for advanced coal-fired power plants - properties and experience. International Journal of Pressure Vessels and Piping. 2008; 85:38-46.

3. Bendick W, Gabriel B, Hahn B and Vandenberghe B. New low alloy heat resistant ferritic steels T/P23 e T/P24 for power plant application. International Journal of Pressure Vessels and Piping. International Journal of Pressure Vessels and Piping. 2007; 84:13-20.
4. Dhooge A and Vekeman J. New generation $2{ }^{1 / 4} \mathrm{Cr}$ steels T/P 23 and T/P 24 weldability and high temperature properties. Welding Research AbroadWRC. 2006; 2(4):31-49.

5. Nawrocki JG, Dupont JN, Robino CV, Puskar JD and Marder AR. The mechanism of stress-relief cracking in a ferritic alloy steel. Welding Journal. 2003; 82(2):25-S-35-S.

6. Nawrocki JG, Dupont JN, Robino CV and Marder AR. The stress-relief cracking susceptibility of a new ferritic steel - part 1: single-pass heataffected zone simulations. Welding Journal. 2000; 79(12):355-S-362-S.

7. Brózda J and Pasternak J. Heat Resisting Steels of the New Generation and Examples of their application in Supercritical Boilers Designed for the Polish Power Plants Instytut Spawalnictwa. Poland: Institute of Welding; 2005. p. 1-14.

8. Nevasmaa P, Salonen J, Holmström S and Caminada S. reheat cracking susceptibility and ductility \& toughness behaviour of modified $2 \%$ $\mathrm{Cr}-\mathrm{Mo}(\mathrm{W}) \mathrm{V}$ P23 steel simulated HAZs and multipass welds made using matching and mis-matching filler metals. VTT Technical Research Centre of Finland: Research Report; 2007;1-53.

9. Nevasmaa P, Salonen J, Holmström S and Caminada S. Heat-affected zone toughness behaviour and reheat cracking susceptibility of affected thermally simulated microstructures in new P23 (7CrWVMoNb9-6) steel. VTT Technical Research Centre of Finland: Research Report. 2006; 1-43.

10. Igarashi $\mathrm{M}$, Yoshizawa $\mathrm{M}$, Matsuo $\mathrm{H}$, Miyahara $\mathrm{O}$ and Iseda A. Long-term creep properties of low C-2,25Cr-1,6W-V-Nb Steel (T23/P23) for fossil fired and heat recovery boilers. Materials Science and Engineering A. in press. doi: 10.1016/j.msea. 2008.05.054.

11. Goldak J, Chakravarti A and Bibby M. A new finite element model for welding heat sources model. Metallurgical Transactions B. 1984; 15B:299-305

12. Yurioka N, Okumura M, Kasuya T and Cotton HJU. Prediciton of HAZ hardness of ferritic steels. Metal Construction. 1987; 19:217R-223R.

13. Nawrocki JG, Dupont JN, Robino CV and Marder AR. The postweld heat-treatment response of simulated coarse-grained heat-affected zones in a new ferritic steel. Metallurgical and Materials Transactions A. 2001; 32A: 2585-2594.

14. Patankar SV. Numerical heat transfer and fluid flow. New York: McGrawHill; 1984.

15. Patankar SV and Spalding DB. A calculation procedure for heat and mass transfer in three-dimensional parabolic flows. International Journal of Heat and Mass Transfer. 1972; 15:1787.

16. Melaaen MC. Calculation of fluid flows with staggered and nonstaggered curvilinear nonortogonal grids - the theory. Numerical Heat Transfer, Part B. 1992; 21 .

17. Karki KC and Patankar SV. A Pressure based calculation Procedure for Viscous Flows at all speeds in Arbitrary Configurations. Numerical Heat Transfer. 1988; 14.

18. Thompson JF, Warsi ZUA and Mastin CW. Numerical grid generation. New York: North Holland; 1985. Appendix C-3. 
Appendix A. Discretization of the energy equation.

The general energy transport equation can be written with the temperature as dependent variable, shown in Equation A1:

$$
\frac{\partial}{\partial t}\left(\rho c_{p} T\right)+\operatorname{div}\left[\rho c_{p}(\vec{u}) T\right]=\operatorname{div}[k(\operatorname{grad}(T))]+S
$$

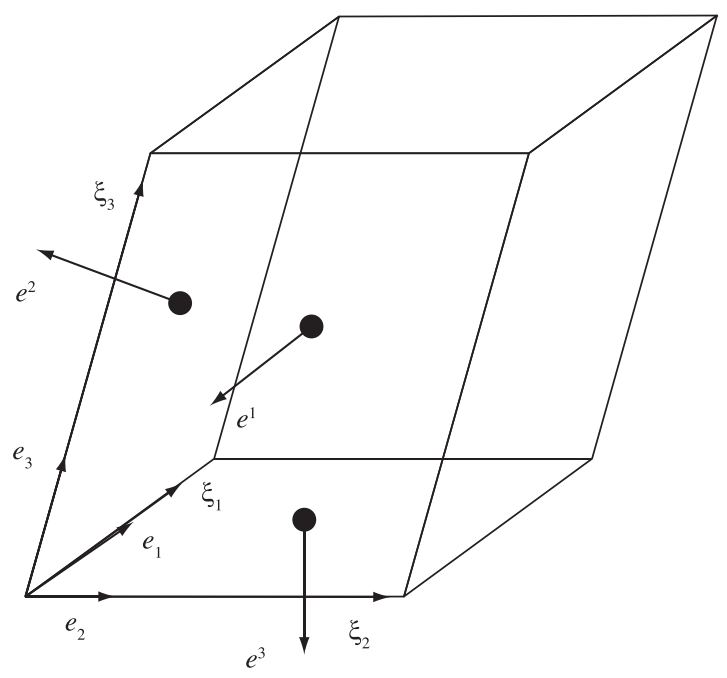

Figure A1. Covariant and contravariant basis vector

Based on Figure A1, lets define $\left(x^{1}, x^{2}, x^{3}\right)$ - Cartesian system and $\left(\xi^{1}, \xi^{2}, \xi^{3}\right)$ - The general curvilinear non-orthogonal system. Two distinct frames of basis vectors can be defined at any point in a curvilinear non-orthogonal system. The so-called covariant basis vectors, that follows the coordinate lines being tangents at any point and the contravariant basis vectors, which are perpendicular to the surface defined by two of the covariant vector. Equations A2 and A4 define the Cartesian components of these base vectors, respectively.

$$
\begin{aligned}
& a_{i}=\frac{\partial x^{k}}{\partial \xi^{i}} I_{k}=J_{i}^{k} I_{k} \\
& J_{i}^{k}=\frac{\partial x^{k}}{\partial \xi^{i}} \\
& a^{i}=\frac{\partial \xi^{i}}{\partial x^{k}} I_{k}=\bar{J}_{k}^{i} I_{k} \\
& \bar{J}_{k}^{i}=\frac{\partial \xi^{i}}{\partial x^{k}}
\end{aligned}
$$

In order to relate the derivatives of the temperature field in these coordinates systems the chain rule is used as follows:

$$
\begin{gathered}
\frac{\partial T}{\partial \xi^{i}}=\frac{\partial x^{j}}{\partial \xi^{i}} \frac{\partial T}{\partial x^{j}}=J_{i}^{j} \frac{\partial T}{\partial x^{j}} \\
\frac{\partial T}{\partial x^{i}}=\frac{\partial \xi^{j}}{\partial x^{i}} \frac{\partial T}{\partial \xi^{j}}=\bar{J}_{i}^{j} \frac{\partial T}{\partial \xi^{j}}
\end{gathered}
$$

The Jacobian determinant of the coordinate transformation is defined by Equation A8 and the rows and columns of the matrix formed by the derivatives of the coordinate transformation gives the necessary information of the coordinate transformation used to express the discretized form of the energy transport equation.

$$
J=\operatorname{det}\left|\begin{array}{lll}
\frac{\partial x^{1}}{\partial \xi^{1}} & \frac{\partial x^{1}}{\partial \xi^{2}} & \frac{\partial x^{1}}{\partial \xi^{3}} \\
\frac{\partial x^{2}}{\partial \xi^{1}} & \frac{\partial x^{2}}{\partial \xi^{2}} \frac{\partial x^{2}}{\partial \xi^{3}} \\
\frac{\partial x^{3}}{\partial \xi^{1}} & \frac{\partial x^{3}}{\partial \xi^{2}} & \frac{\partial x^{3}}{\partial \xi^{3}}
\end{array}\right|
$$


The Cartesian components of the contravariant basis vector are evaluated by the following expression:

$$
H_{M}=884 C\left(1-0.3 C^{2}\right)+294
$$

Therefore, the Jacobian of the transformation being evaluated, all necessary information can be evaluated. The components of the Jacobian matrix can be numerically determined (computational space approach) or by the direct calculation of the area vectors and volume in the physical space (physical space approach). We have chosen the computational space approach.

The covariant and contravariant metric tensors components can be written from the basis vectors components, thus the nine components are:

$$
\begin{aligned}
& g_{i j}=a_{i} \cdot a_{j}=J_{i}^{k} J_{j}^{k} \\
& g^{i j}=a^{i} \cdot a^{j}=\bar{J}_{k}^{i} \bar{J}_{k}^{j}
\end{aligned}
$$

The area vectors generated by two of the covariant vectors are given by:

$$
A^{(i)}=a_{j} \times a_{k}(\mathrm{i}, \mathrm{j}, \mathrm{k} \text { cyclic })
$$

The geometric diffusion coefficient is defined by:

$$
G^{i j}=\frac{A_{k}^{i} A_{k}^{j}}{J}
$$

With the above equations all the necessary information of the coordinate transformation is given. These equations relate the physical space with the computational space and this is currently used to obtain the discretized form of the energy conservation equation, Equation A1. In the next section, the discretized form of a general state variable is deduced and then the discretized form of the momentum equations are presented in terms of the covariant projections.

\section{Discretization of the general energy conservative equation}

The discretization of the general energy conservation equation is based on the finite volume method ${ }^{14}$. The coordinate invariant Equation A14 is integrated over a general control volume in the physical space and then the Gauss divergence theorem is applied to transform the volume integral into a surface integral.

$$
\int_{\delta t} \int_{\delta V} \frac{\partial\left(\rho C_{p} T\right)}{\partial t} d v d t+\int_{\delta t} \int_{\delta V} \operatorname{div}\left(\rho \vec{u} C_{p} T-k \operatorname{grad} T\right) d v d t=\int_{\delta t} \int_{\delta V} S_{\varphi} d v d t
$$

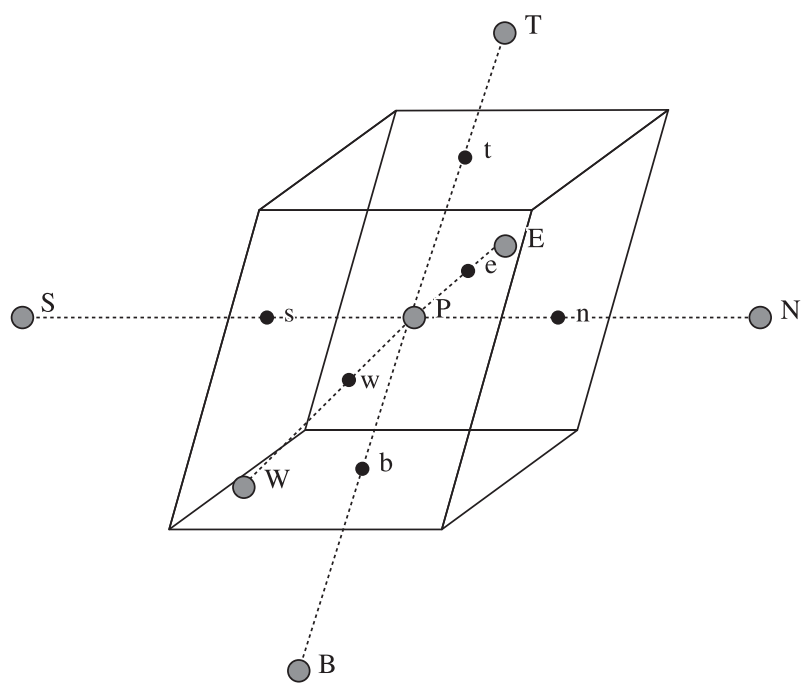

Figure A2. Schematic molecule of a 3-D control volume

Figure A2 illustrates the concept of the finite volume method, where the average value of the dependent variable is assumed to prevail over all the control volume centered in the point P. Notation presented in Figure A2 is as follows: w-west face, e-east face, s-south, n-north, b-bottom and t-top. For the computational molecule similar notation applies W-West, E-east, S-south, N-north, B-bottom and T-top volumes. Hence, from now this notation will be used to identify the faces of the control volumes while the capital letters will identify the neighborhood points. In order to simplify the integral form of the conservation Equation A14. Lets define a flux tensor, F, as follows: 


$$
F=\rho \vec{U} C_{p} T-k \nabla T
$$

Hence the control volume integration of Equation A14, without the transient term, is given by using Equation A15 and the Gauss theorem. The transient terms will be detailed later.

$$
\begin{aligned}
& \left.F \cdot A\right|_{e}-\left.F \cdot A\right|_{w}+\left.F \cdot A\right|_{n}-\left.F \cdot A\right|_{s}+\left.F \cdot A\right|_{t}-\left.F \cdot A\right|_{b}=S_{c}+S_{P} T_{P} \\
& \left.F \cdot A\right|_{e}=\int_{A_{e}} F \cdot d A=\left.\left(\rho U \cdot A^{(1)} C_{p} T-k A^{(1)} \cdot \nabla T\right)\right|_{A_{e}}=\left.F^{1}\right|_{e} \\
& \left.F \cdot A\right|_{n}=\int_{A_{n}} F \cdot d A=\left.\left(\rho U \cdot A^{(2)} C_{p} T-k A^{(2)} \cdot \nabla T\right)\right|_{A_{n}}=\left.F^{2}\right|_{n} \\
& \left.F \cdot A\right|_{t}=\int_{A_{t}} F \cdot d A=\left.\left(\rho U \cdot A^{(3)} C_{p} T-k A^{(3)} \cdot \nabla T\right)\right|_{A_{t}}=\left.F^{3}\right|_{t} \\
& \left.F^{1}\right|_{e}=\left(\rho U^{1} C_{p} T-k\left(G^{11} \frac{\partial T}{\partial \xi^{1}}+G^{12} \frac{\partial T}{\partial \xi^{2}}+G^{13} \frac{\partial T}{\partial \xi^{3}}\right)\right)_{A_{e}} \\
& \left.F^{2}\right|_{n}=\left(\rho U^{2} C_{p} T-k\left(G^{21} \frac{\partial T}{\partial \xi^{1}}+G^{22} \frac{\partial T}{\partial \xi^{2}}+G^{23} \frac{\partial T}{\partial \xi^{3}}\right)\right)_{A_{n}} \\
& \left.F^{3}\right|_{t}=\left(\rho U^{3} C_{p} T-k\left(G^{31} \frac{\partial T}{\partial \xi^{1}}+G^{32} \frac{\partial T}{\partial \xi^{2}}+G^{33} \frac{\partial T}{\partial \xi^{3}}\right)\right)_{A_{t}}
\end{aligned}
$$

Similar expressions is given for $\mathrm{w}, \mathrm{s}$ and $\mathrm{b}$ faces. $U^{1}, U^{2}$ and $U^{\mathcal{\beta}}$ are the normal velocities to the faces e, $\mathrm{n}$ and $\mathrm{t}$, respectively.

Before present the final form of the discretized conservation equation the transient term is included. In this point we have to make a decision of which method of discretization of the time derivatives. Several methods have been proposed in the literature ${ }^{14-18}$, however for non-linear problems the fully implicit method is selected due to its stability and the guarantee of always meaningful solution even for strong non-linearly problems. Therefore, it is a suitable method to be applied for the welding process simulation. In this scheme the "new" value of the dependent variable is assumed to be same throughout the time step. The transient terms is then discretized as:

$$
\int_{\delta v} \frac{\partial\left(\rho C_{p} T\right)}{\partial t} d v \approx \frac{\left(J_{p} \rho C_{P} T-J_{p}^{0} \rho_{p}^{0} C_{p}^{0} T_{P}^{0}\right)}{\Delta t}
$$

If the above equations are substituted into Equation A14 a general discretized equation is the result:

$$
a_{P} T_{P}=a_{W} T_{W}+a_{E} T_{E}+a_{B} T_{B}+a_{T} T_{T}+a_{S} T_{S}+a_{N} T_{N}+b
$$

where

$$
a_{P}=a_{W}+a_{E}+a_{B}+a_{T}+a_{S}+a_{N}+J_{p} \frac{\rho C_{p}}{\Delta t}-S_{P}
$$

and

$$
\begin{aligned}
b=b_{N O}+S_{C}+J_{p}^{0} \frac{\rho^{0} C_{p}^{0}}{\Delta t} T_{p}^{0} \\
b_{N O}=\left[\Gamma G^{12} \frac{\partial T}{\partial \xi^{2}}+\Gamma G^{13} \frac{\partial T}{\partial \xi^{3}}\right]_{w}^{e}+\left[\Gamma G^{21} \frac{\partial T}{\partial \xi^{1}}+\Gamma G^{23} \frac{\partial T}{\partial \xi^{3}}\right]_{S}^{n} \\
+\left[\Gamma G^{31} \frac{\partial T}{\partial \xi^{1}}+\Gamma G^{32} \frac{\partial T}{\partial \xi^{2}}\right]_{b}^{t}
\end{aligned}
$$

The coefficients in Equation (A24) are determined by the power law scheme of Patankar ${ }^{14-17}$, as in Table A1: 
Table A1. Power law coefficients for the discretized general conservative equation.

\begin{tabular}{|c|c|}
\hline$a_{E}=D_{e} A\left(P_{e}\right) ; P_{e}=\frac{C_{e}^{1}}{D_{e}} ; D_{e}=\left.k G^{11}\right|_{e}$ & $a_{W}=D_{w} A\left(-P_{w}\right) ; P_{w}=\frac{C_{w}^{1}}{D_{w}} ; D_{w}=\left.k G^{11}\right|_{w}$ \\
$A\left(P_{e}\right)=\min \left\langle 0,\left(1-0.1\left|P_{e}\right|\right)^{5}\right\rangle+\min \left\langle 0,-P_{e}\right\rangle$ & $A\left(-P_{w}\right)=\min \left\langle 0,\left(1-0.1\left|-P_{w}\right|\right)^{5}\right\rangle+\min \left\langle 0,+P_{w}\right\rangle$ \\
\hline$a_{N}=D_{n} A\left(P_{n}\right) ; P_{n}=\frac{C_{n}^{2}}{D_{n}} ; D_{n}=\left.k G^{22}\right|_{n}$ & $a_{S}=D_{s} A\left(-P_{s}\right) ; P_{s}=\frac{C_{s}^{2}}{D_{s}} ; D_{s}=\left.k G^{22}\right|_{s}$ \\
$A\left(P_{n}\right)=\min \left\langle 0,\left(1-0.1\left|P_{n}\right|\right)^{5}\right\rangle+\min \left\langle 0,-P_{n}\right\rangle$ & $A\left(-P_{s}\right)=\min \left\langle 0,\left(1-0.1\left|-P_{s}\right|\right)^{5}\right\rangle+\min \left\langle 0,+P_{s}\right\rangle$ \\
\hline$a_{T}=D_{t} A\left(P_{t}\right) ; P_{t}=\frac{C_{t}^{3}}{D_{t}} ; D_{t}=\left.k G^{33}\right|_{t}$ & $a_{B}=D_{b} A\left(-P_{b}\right) ; P_{b}=\frac{C_{b}^{3}}{D_{b}} ; D_{b}=\left.k G^{33}\right|_{b}$ \\
$A\left(P_{t}\right)=\min \left\langle 0,\left(1-0.1\left|P_{t}\right|\right)^{5}\right\rangle+\min \left\langle 0,-P_{t}\right\rangle$ & $A\left(-P_{b}\right)=\min \left\langle 0,\left(1-0.1\left|-P_{b}\right|\right)^{5}\right\rangle+\min \left\langle 0,+P_{b}\right\rangle$ \\
\hline
\end{tabular}

Nomenclature

\begin{tabular}{|c|c|c|}
\hline$A^{(1)}:$ & Area vectors generated by two covariant vectors & {$\left[\mathrm{m}^{2}\right]$} \\
\hline$A_{k}^{i}:$ & Cartesian components of the area vectors & {$\left[\mathrm{m}^{2}\right]$} \\
\hline$a^{i}:$ & Contravariant basis vector & {$[\mathrm{m}]$} \\
\hline$a_{i}:$ & Covariant basis vector & {$[\mathrm{m}]$} \\
\hline$a_{k}:$ & Coefficients in discretized equation (k:W,E,S,N,B,T,P) & \\
\hline$b:$ & Independent part of the linearized source term & \\
\hline$b_{N O}:$ & Non-orthogonal part of the linearized source term & \\
\hline$C^{i}:$ & Convective normal flux & {$[\mathrm{kg} / \mathrm{s}]$} \\
\hline$F:$ & Flux tensor & \\
\hline$G^{i j}:$ & - Cartesian components of geometric diffusion coefficient & \\
\hline$g^{i j}:$ & - Cartesian components of contravariant metric tensor & {$\left[\mathrm{m}^{-2}\right]$} \\
\hline$g_{i j}:$ & - Cartesian components of covariant metric tensor & {$\left[\mathrm{m}^{2}\right]$} \\
\hline$I_{k}:$ & - Cartesian unit vectors & {$[-]$} \\
\hline$J:$ & - Jacobian determinant of coordinate transformation (volume in physical space) & {$\left[\mathrm{m}^{3}\right]$} \\
\hline Pe: & - Peclet number & \\
\hline$S_{\phi}:$ & - Source term for Eq. (2.1) & \\
\hline$t:$ & Time & {$[\mathrm{s}]$} \\
\hline$\vec{U}_{i}:$ & - Velocity vector of moving grid & {$[\mathrm{m} / \mathrm{s}]$} \\
\hline$x^{i}:$ & Cartesian coordinate system & {$[\mathrm{m}]$} \\
\hline
\end{tabular}

Greek symbols

\begin{tabular}{|c|l|c|}
\hline$\xi^{i}:$ & Covariant coordinate system & {$[\mathrm{m}]$} \\
\hline$\rho:$ & Density & {$\left[\mathrm{kg} \cdot \mathrm{m}^{-3}\right]$} \\
\hline
\end{tabular}

